\title{
Des métamorphoses de l'écriture du poète-arbre-corps masculin torturé dans la poésie de Federico García Lorca
}

JOCELYNE AUBÉ-BOURLIGUEUX'

1 Jocelyne Aubé-Bourligueux- Professeur Emérite de l'Université de Nantes - Associé du Laboratoire CRINI (Centre de Recherche sur les Identités Nationales et l'Interculturalité), Nantes, Faculté des Langues et Cultures Etrangères. jocelyne.aube-bourligueux@univ-nantes.fr 


\section{RESUME}

L'objectif de cette étude est d'analyser l'effet que l'image du peuplier de l'enfance de Lorca a pris dans sa correspondance et sa production littéraire tout au long de sa vie. Ce sont ces images qui ont accompagné l'homme jusqu'au bout, sans jamais cesser de jouer auprès du poète un rôle créateur de première importance. II s'agit de trouver les multiples résonances symboliques dont le peuplier est l'expression d'une dualité fondamentale de cet homme-arbre, ce poète-arbre-corps masculin torturé toujours à la recherche d'une réponse à son inquiétude métaphysique.

\section{- MOTS-CLES}

Corps, arbre, correspondance, poésie, García Lorca.

\section{- RESUMO}

O objetivo deste estudo é analisar o efeito que a imagem dos choupos da infância de Lorca assumiu em sua correspondência e em sua produção literária ao longo de sua vida. São estas imagens que acompanharam o homem até o final, sem jamais cessar de representar para o poeta um papel criativo de primeira importância. Trata-se de encontrar as múltiplas ressonâncias simbólicas das quais o choupo é a expressão de uma dualidade fundamental deste homem-árvore, deste poeta-árvore-corpo masculino torturado e sempre a procura de uma resposta a sua inquietude metafísica.

\section{- PALAVRAS-CHAVE}

Corpo, árvore, correspondência, poesia, García Lorca.

- ¿Mi vida? ¿Es que yo tengo vida? Estos mis años, todavía me parecen niños. Las emociones de la infancia están en mí. Yo no he salido de ellas. Contar mi vida sería hablar de lo que soy, y la vida es un relato de lo que se fue. Los recuerdos, hasta los de mi alejada infancia, son en mí un apasionado tiempo presente...

-Ma vie? Ai-je une vie? Les ans, ces ans que j'ai me paraissent appartenir encore à l'enfance.

Les émotions de l'enfance sont en moi. Je n'en suis pas sorti et elles y restent. Raconter ma vie serait parler de ce que je suis, or la vie est un récit de ce qui s'en est allé. Et les souvenirs, même ceux de ma plus lointaine enfance, sont toujours en moi un temps présent passionné....

-Y se lo contaré. Es la primera vez que hablo de esto, que siempre ha sido mío solo, íntimo, tan privado, que ni yo mismo quise nunca analizarlo. Siendo niño, viví en pleno ambiente de naturaleza. Como todos los niños, adjudicaba a cada cosa, mueble, objeto, árbol, piedra, su personalidad. Conversaba con ellos y los amaba. En el patio de mi casa había unos chopos. Una tarde se me ocurrió que los chopos cantaban. El viento, al pasar por entre sus ramas, producía un ruido variado en tonos, que a mí se me antojo musical. Y yo solía pasarme las horas acompañando con mi voz la canción de los chopos...

...« Je vais vous raconter. C'est la première fois que j'en parle, parce que c'est quelque chose qui n'appartient qu'à moi, quelque chose de si personnel, de si intime, de si privé, que pas même moi n'ai voulu l'analyser; non, jamais. Tout enfant, je vécus dans une atmosphère naturelle, en pleine nature. Comme tous les enfants, j'attribuais une personnalité propre à chaque chose. Je conversais avec chacune en 
particulier, avec amour...Dans le patio de ma maison, il y avait des peupliers. Une après-midi, il m'apparut que les peupliers chantaient. Le vent, en passant à travers leurs branches, produisait un son aux tonalités variées qui résonna en moi, musical. Et je pris l'habitude de passer des heures à écouter la chanson des peupliers....Un beau soir, je m'arrêtai net, stupéfait. Quelqu'un prononçait mon prénom en séparant les syllabes, comme s'il épelait : «Fe...de...ri...co...Je regardai tout autour mais ne vis personne. Cependant, dans mes oreilles, mon nom continuait à striduler. Après avoir écouté un long moment, je trouvai la cause : C'étaient les branches d'un vieux peuplier qui, en se frottant entre elles, produisaient un bruit monotone, plaintif, qui à moi me parut être mon prénom... »²

C'est en fait dans une entrevue unique en son genre, réalisée avec le journaliste José R. Luna à Buenos Aires, le 10 mars 1934 que l'auteur en déplacement-tournée en Argentine raconte - une fois n'est pas coutume - ce souvenir absolument personnel, devenu l'un des plus marquants de son enfance à l'écho de certains autres, ce jour là curieusement révélés... L'épisode ici cité, vient témoigner de la présence insistante dans la mémoire de l'homme de trente-six ans d'un événement précis, très ancien, lié à des arbres eux-mêmes précisément nommés. Ceux qui semblent l'avoir ainsi tellement marqué sont, dit-il, les grands et gros peupliers de son propre jardin d'autrefois. À travers les impressions personnelles si bien conservées, soudain restaurées afin d'être proposées rétrospectivement pour de mystérieuses raisons d'ordre fantasmatique, l'évocation faite, remontée du lointain passé, est liée à une double série de sensations visuelles et musicales. En effet, à la vue des branches agitées par la brise s'ajoute alors les sons-syllabes de ce souffle tiède qui, sous l'effet de l'imagination débordante du petit garçon d'alors - et que « Federico » avouera beaucoup plus tard être d'une certaine façon resté -, continue de lui donner l'impression d'une mélodie identitaire. Lesdits arbres n'avaient-ils pas agité devant ses yeux et modulé à son oreille, durant des instants à jamais précieux, le chant syllabique harmonieux de son prénom?

Pour sa part, la lecture de l'ensemble de la correspondance, comme de la production littéraire de García Lorca, va bientôt montrer que le peuplier, d'abord sous la forme du massif peuplier noir du chopo du patio où il jouait jadis, mais aussi des álamos, les grands peupliers blancs du village de Fuente Vaqueros où il vécut durant quelque neuf années avant son déménagement pour Grenade, occupe une place de choix partout, en compagnie de ceux de la Véga dans laquelle il se promenait librement au contact direct de la nature. Ces deux espèces végétales, avec d'autres ultérieurement découvertes, accompagneront en réalité l'homme jusqu'au bout de son parcours humain et poétique, sans jamais cesser de jouer auprès de l'être vital et de son double créateur un rôle de première importance. Car il s'agit là d'arbres offrant de longue date, à qui va la chercher, la grande variété culturelle de leurs multiples résonances symboliques. Mais tandis que les légendes grecques présentent déjà le

\footnotetext{
2 Toutes les citations des poèmes, proses, déclarations et lettres de l'auteur sont extraites des Oeuvres Complètes de Federico García Lorca, Bibliothèque de la Pléiade en deux volumes (TI et TII), édition établie par André Belamich, N. R. F., édit. Gallimard, 1981. Traductions de A. Belamich, J. Comincioli, C. Couffon, R. Marrast, B. Sesé, J. Supervielle. La présente déclaration est extraite d'une interview du 10 mars 1934, «La vie de García Lorca, poète», in TII de la présente édition, pp. 853-54. Pour la version espagnole, voir Federico García Lorca,, Obras completas, recopilación y notas de Arturo del Hoyo, Madrid, Aguilar, 1954 et svtes. Pour ce travail, a été utilisée la 22e édition (celle de 1986), en $3 \mathrm{vol}$ (= OCl; OCII, OCIII) La citation qui précède se situe in OCIII, p. 1753.
} 
peuplier comme l'expression d'une dualité ontologique fondamentale, cet arbre au demeurant associé à une descente aux enfers (l'Hadès) dont témoignent les deux faces opposées par leur teinte et leur texture de ses feuilles, est par ailleurs traditionnellement associé aux forces régressives de la nature. Peuplier-chopo puis peuplier-álamo du jardin-verger du moi secret : deux espèces charnellement et spirituellement plus que toutes autres lorquiennes par excellence, donc, quand on sait que chacun d'eux symbolise généralement le souvenir de l'hier plus que l'espérance du demain ; ou en appelle davantage au retour du temps passé qu'à l'avenir des renaissances... Sans oublier, bien sûr, l'aspect tourmenté, voire torturé, que présente au regard de l'auteur la forme qui se dresse à l'horizon de son être intime de musicien-poète...

\section{«Una Campana »: où la créativité lorquienne fait résonner le 'peuplier' de l'amour blessé de l'écho poétique de l'être crucifié.}

En Octobre 1920, un texte en vers du Livre de Poèmes fait parvenir jusqu'au lecteur le son de vers déchirés, oniriquement adressés par le poète, comme c'est souvent le cas au fil de l'oeuvre, à un arbre, mais pas n'importe lequel : car ce 'peuplier' vers lequel s'élève la plainte et convergent les regards du locuteur est issu de cet ancien jardin du moi de l'enfance qui précède : espace planté de troncs ornés de ramures jadis mélodieuses, confident et compagnon de jeu, maintenant devenu prétexte artistique à toutes sortes d'essais.

Or, cette composition intitulée «Une Cloche» dans la traduction de la Pléiade («Una Campana» dans l'original espagnol'3) va curieusement dévoiler, au détour des lignes, le vrai visage du moi lyrique brisé, désormais identifié au «chopo» du patio de son enfance, mais également martyrisé à travers lui, dans son être profond. En ce sens, résonne ici l'écho très singulier de cette voix au timbre christique que le créateur donne à entendre depuis le début de son oeuvre et qui ne se taiera plus, y compris quand d'autres témoignages d'ordre vital, en particulier dans la correspondance, viendront confirmer auprès des amis, de manière plus ou moins avouée, la nature des véritables sentiments de l'homme, ou la cause réelle de ses maux, sur le plan physique, affectif, moral, spirituel :

« Una campana serena / crucificada en su ritmo / define a la mañana con peluca de niebla y arroyos de lágrimas. / Mi viejo chopo / turbio de ruiseñores / esperaba / poner entre las hierbas sus ramas / mucho antes que el otoño lo dorara. / Pero los puntales de mis miradas / lo sostenían. / i Viejo chopo, aguarda ! / i No sientes la madera de mi amor desgarrada ? / Tiéndete en la pradera / cuando cruja mi alma, / que un vendaval de besos / y palabras / ha dejado rendida, / lacerada "4.

Dès l'ouverture, c'est une cadence musicale très particulière qui s'impose sou-

\footnotetext{
3 Federico García Lorca. Libro de Poemas, «Una Campana», Octubre de 1920, in OCl, p. 80.

4 Livre de Poèmes, "Une cloche », Octobre 1920, «Une cloche sereine / Crucifiée dans son rythme / Dessine le matin / En perruque de brouillard / Et ruisseaux de larmes. / Mon vieux peuplier / Trouble de rossignols / Espérait / Coucher parmi les herbes / Ses branches / Bien avant que l'automne / Ne vínt le dorer. / Mais l'appui / de mes regards / le soutenait. / Attends, vieux peuplier ! / Vois-tu comme le bois de mon amour se fend ? Tu t'étendras au champ / Lorsque craquera mon âme / Qu'un ouragan de mots / Et de baisers / A laissé sans force, / Déchirée", Livre de Poèmes, La Pléiade, I, op. cit., p. 60. II arrivera qu'une mention particulière signale une modification ou une retraduction personnelle des vers cités.
} 
dain à l'oreille de l'auditeur, à travers le tintement singulier perçu de cette unique 'cloche' matinale. Car le son à première écoute pacifié, sur lequel est poétiquement modelé l'écho en train de s'élever lentement au dessus du paysage émotionnel, se double aussitôt d'un rythme venu rectifier celui des coups portés, mais aussi contraster leur signification humaine subjective, par l'emploi du participe «crucifiée». L'élan rompu ainsi parvenu jusqu'à l'auteur, dans son présent textuel, est en réalité entendu autrement, parce que déformé, transformé et empreint d'une tristesse qui se fait ici le véhicule sonore de la lourde croix apparemment portée par lui, à l'automne 1920. La 'sérénité' apparente de la musique du premier vers disparaît, en effet, dès que retentit ce martellement à la tonalité sinistrement répétitive d'un glas : comme asséné à chaque fois par un battant intérieur qui enfoncerait un clou dans le vif ${ }^{5}$ de l'être martyrisé, imprimant au profond de sa chair la cadence d'un lent supplice.

Dans cette perspective, la lugubre référence supposée détruit d'emblée la promesse éphémère amorcée, d'un jour neuf et prometteur d'une espérance nouvelle. D'ailleurs, ainsi que le montrent les vers suivants, le jour qui se lève est lui-même bientôt marqué au sceau d'un destin identique et d'un sort funeste commun, quand sous l'effet de mystérieuses correspondances souterraines, les sons heurtés jusqu'à briser chacun des membres du moi lyrique se font à ce point le calque auditif du paysage environnant, qu'ils en dessine sans tarder les contours essentiels et en 'définissent' la silhouette à la fois douloureusement personnifiée et tragiquement travestie.

Dans un premier temps, grâce à l'approche esthétique très particulière mise en oeuvre, le ton élégiaque suggère l'agonie et le trépas audible d'un être, de la sorte musicalement esquissées sous l'apparition d'une aube voilée ou masquée («perruque de brouillard»), à son tour reflet mimétique d'un deuil humain lourd de peine («Et ruisseaux de larmes»). Mais de quel mort lente est-il question maintenant de traduire l'action en marche? Et de quel futur défunt s'agit-il de pleurer la disparition imminente, au seuil d'une telle aurore sans horizon visible aucun? De la fin prochaine qui touche son 'peuplier', selon le témoignage du locuteur de première personne présent dès le sixième vers ; disparition à venir qui le concerne directement aussi, à l'arrivée du mouvement créateur envisagé. Car le destin fatal de cet arbre, dont le sujet lyrique se sent et se veut en quelque sorte le double charnel autant que spirituel, apparaît désormais absolument inséparable du sien.

Le moi poétique ne s'introduit-il pas comme corps blessé et âme souffrante à ses côtés, comme pour mieux l'assister, l'accompagner, voire partager jusqu'au bout ? Sans doute, si l'on songe que la disposition ryhtmique du début du texte lorquien contribue à conférer au morceau dans son ensemble, non seulement sa forme spécifique, à tous les niveaux originale, mais encore sa signification profonde de sacrifice peu à peu accepté, au sein d'une nature évocatrice de la mise en croix d'un homme et d'un peuplier emblématique : amis et confidents ensemble voués à subir la même condamnation à mort.

Or, il semble que le 'chopo' soit ici en train de précéder de peu, dans l'agonie, l'artiste lancé dans un difficile combat de dernière heure : cœur malmené au creux de son écorce, sur le point de succomber sous les traits qui pleuvent et se plantent tels de nouveaux clous-dards dans ses membres-branches, pour l'entraîner inéluctablement à sa propre perte.

\footnotetext{
5 L'auteur utilise de ce point de vue la métaphore qui précède: «la madera de mi amor» (« le bois de mon amour »).
} 
Un mois auparavant, en août 1920, dans un poème au titre significatif de «In Memoriam ", García Lorca contemplait déjà l'arbre du jardin d'autrefois, auquel il s'adressait en ces termes ${ }^{6}$ :

«Dulce chopo, / dulce chopo, / te has puesto / de oro. / Ayer estabas verde, / un verde loco / de pájaros / gloriosos. / Hoy estás abatido/ bajo el celo de agosto / como yo bajo el cielo / de mi espíritu rojo. / La fragancia cautiva / de tu tronco / vendrá a mi corazón / piadoso. / iRudo abuelo del prado ! / Nosotros / nos hemos puesto / de oro.

D'un bout à l'autre de cette brève composition, également présentée sous la forme d'un dialogue, bien qu'elle constitue en réalité un monologue intime, le regard porté sur le patriarche vieillissant restait empreint de tendresse confiante. En dépit du constat qui s'imposait, selon lequel un automne précoce avait remplacé le printemps de l'enfance, ou l'été de la jeunesse complice. Une autre saison s'y était substituée, lourde de sombres menaces 'sous le ciel d'août', en dépit du riche éclat dont paraîssait brillait encore le peuplier, dans les premiers vers. Apparemment, la palette colorée à base de jaune et de rouge du peintre correspondait à celle utilisée par le prosateur ou le correspondant, pour décrire la magnificence des soirées de Grenade et des ciels de la Véga durant toute cette période, voire même après ${ }^{7}$; mais le vert s'en était éclipsé avec la disparition des nids et de leurs habitants à plumes.

À l'évocation gongorisante antérieure du 'doux peuplier' au 'vert fou d'oiseaux glorieux', semble correspondre maintenant celle du 'vieux peuplier'trouble de rossignols'; tandis que les vers annonciateurs du déclin 'Bien avant que l'automne / Ne vînt le dorer' paraissent se faire à présent l'écho lumineux de ceux qui affirment de leur côté : 'Te voici / Tout doré'. Dans les deux cas, l'antique abri mélodieux, peuplé de vies, de chants et de bruissements d'ailes s'est tu dans le soir immobile, à l'heure du changement saisonnier venu affliger l'arbre comme l'homme, unis tous deux par le 'nous' de première personne du pluriel, au sein d'un ultime embrasement crépusculaire précédant la tombée imminente de la nuit. Or, après avoir été la source secrète des subtils et essentiels effluves d'un 'parfum captif', jadis susceptible de s'envoler vers le voyant en attente de quelque révélation initiatique de nature affective, voici l'arbre obligé de renoncer au secours de dernière minute porté par le poète, incapa-

\footnotetext{
6 Libro de Poemas, «In Memoriam », agosto de 1920, op. cit., p. 65. Cf. Livre de Poèmes, op. cit., p. 49. Doux peuplier /Doux peuplier, /Te voici/ Tout doré. Hier tu étais vert,/D'un vert fou /D'oiseaux /Glorieux. Aujourd'hui tu gis /Sous le ciel d'août Comme moi sous le ciel /De mon esprit pourpre. / Le parfum captif /De ton écorce Viendra vers mon coeur /Aimant. /Rude aïeul des prés! Tous deux /Nous voici /dorés.

7 Du moins, le registre pictural utilisé rappelle-t-il singulièrement certaines évocations de Grenade, à travers le regard ému porté par Federico sur le paysage environnant. II n'en serait pour preuve que ces lignes datées de novembre 1919 : «Grenade est merveilleuse, toute pleine d'or automnal». Cf. Correspondance, à Ángel Barrios, Grenade 1919, La Pléiade I,. op. cit., p. 987. Nous pourrions dire la même chose en ce qui concerne la teinte qui, l'été, empourpre parfois la nature, provoquant l'admiration du spectateur : «Si tu voyais comme la montagne est belle ! Toute rouge et la Véga que l'on distingue de ces balcons, toute dans l'ombre»(Correspondance à Regino Sáinz de la Maza, été 1921 ? idem, p. 995). Peut-être un mois plus tard, l'épistolier dira encore, dans une lettre envoyée à Melchor Fernández Almagro: «tu ne peux imaginer la joie que j'ai eue à revoir la Véga qui tremblait sous un délire de brume azurée»; in Correspondance (Asquerosa, juillet 1921), op., cit., p. 996. Comme au début de sa vie, García Lorca reste à ce stade infiniment sensible partout au charme de l'univers grenadin et andalou, toujours source pour l'homme et le créateur de sensations visuelles et auditives singulières, ainsi que d'émotions multiples, multipliées. II en sera d'ailleurs constamment ainsi par la suite. Cf. la version espagnole des missives dont les dates d'expédition peuvent changer, in Epistolario completo I y II, éd. de Christopher Maurer y Andrew A. Anderson, Madrid, Cátedra, 1997. Respect. , Carta a Ángel Barrios (1), Graná (16 o 17 nov. 1919), op. cit., p. 62 ; Carta a R. Sáinz de la Maza (5), Granada, 16 iseptiembre ? 1922 ; op. cit., p. 158 ; Carta a M.Fernández Almagro (1), Asquerosa, ¿finales de junio ?, 1921, op. cit., p. 119.
} 
ble de 'l'étayer' des yeux ni de le soutenir à la pointe du cœur, durant sa chute. Menacé d'une mort fruit d'une immense lassitude et issue de la difficulté d'aimer, ou plutôt de l'impossibilité d'être aimé, rien ne permet plus à l'homme d'arrêter l'effondrement du corps arborifère devenu celui de son propre corps, métaphoriquement chair érotisée de peuplier vaincu.

Comment celui qui interrroge alors, aussi désarmé que désespéré : «Vois-tu comme le bois de mon amour se fend ? ", avant de prédire le pire en terme d'effet de tornade dévastatrice, et de tourmente cyclonique soufflant sur son être végétal : «Tu t'étendras au champ / Lorsque craquera mon âme / Qu'un ouragan de mots / Et de baisers / A laissé sans force, / Déchirée », pourrait-il encore lui prêter main forte, du geste ou de la voix ? Alors que son tronc défaillant se fissure de partout, et que sa tête aux frondaisons vieil or éclate sous des orages de passion dévastatrice? Une sorte d'union substantielle assimile donc maintenant l'homme à l'arbre sur le déclin, afin de mieux les rassembler dans le pré, emportés qu'ils vont être ensemble par un même coup de tempête de sentiments, dès que l'être crucifié au son de la cloche qui sonne ${ }^{8}$ en fait le glas de son 'âme déchirée', en aura donné le signal.

\section{«Chopo muerto» (1920) : l'arbre-corps de la maladie d'amour-mélancolie d'absence, chez Federico García Lorca.}

Dans ce poème dont l'intitulé traduit est « Peuplier mort », le lecteur se trouve soudain confronté à une expérience artistique très particulière, si ce n'est unique en son genre : quand le créateur Federico García Lorca, jeune homme alors âgé de vingt-et un ans, le met brusquement en présence du spectacle, soudain ressenti comme agonique, du même arbre devenu l'objet par excellence d'une nouvelle et émouvante élaboration littéraire. Pour sa part, 'le peuplier' du paysage familier ne cesse, comme il a été dit, d'accompagner partout «Federico» homme et artiste, depuis son enfance andalouse. Ainsi profilait-t-il déjà sa silhouette reconnaissable, au fil des divers essais ébauchés par le jeune excursionniste de l'Université, partout en train de consigner au passage les notes de ses Impressions et Paysages. Lors de chacune de ses réapparitions visuelles et sonores sous la plume de l'artiste, il jouera de la sorte un rôle de plus en plus central : d'ami fraternel dans le partage de la douleur, de confident solidaire dans l'expression de la peine, si ce n'est de médiateur-messager toujours à l'écoute, chargé de traduire à travers ses métamorphoses successives celles d'une forme artistique elle-même en perpétuelle mutation.

Dans ce cas précis toutefois, la rencontre avec 'son' arbre du poète andalou lancé sur le chemin d'une écriture sans cesse en évolution prend un caractère mortel. Quand la voix poématique que n'abandonne jamais des accents vitaux authentiques va conférer au peuplier un sort fatal, à l'heure où l'arbre cristallisera d'un point de

\footnotetext{
8 Le rythme dont résonne cette cloche est l'écho même de la vibration poétique intérieure, rompue et triste du "crucifié». Ici se dessine déjà la réalité du Lorca artiste parcourant son propre chemin de croix. Dès la «Ballade de la Placette», nous entendons : «Les enfants : Que contient ton divin/Coeur en fête? Moi :Un glas qui sonne/ Au fond du brouillard " (Livre de Poèmes, op. cit., p. 71). Dans «Poèmes tardifs", nous écoutons aussi dire : "La voix de la cloche/me démantèle», in En marge du Livre de Poèmes, idem, p. 121. Cf . «Balada de la placeta (1919), Libro de Poemas, op. cit., p. 96. "Poemas tardíos ", Ceci annonce déjà de loin, par exemple, les visions postérieures de l'écorché vif qu'est «l'homme aux veines» du scénario du Voyage à la Lune, ou encore celle du «Nu Rouge» de la pièce Le Public. Cf. respectivement Marie Laffranque, F. G. Lorca, Viaje a la Luna, Loubressac, Braad Ed., 1980 ; F. G. Lorca, El Público, Edic. Cátedra, Letras hispánicas, 1987.
} 
vue esthétique l'existence d'une souffrance secrète, elle-même inéluctablement en marche : angoisse créatrice dont le faiseur de vers s'efforcera d'exprimer, au fil d'un chant élégiaque, la mélancolique résonnance existentielle. Ne s'agira-t-il pas là de suggérer, à l'écho du destin de l'arbre du 'patio' d'antan, le déroulement inexorable d'une disparition imminente, accompagnée des ravages résultant d'une mort lente pratiquement déjà consommée?

Nul ne sait en quelle saison affectivement complice du devenir menacé d'un arbre peu à peu vaincu par une maladie incurable, est exactement celle retenue par Federico García Lorca, dans sa vision du Livre de Poèmes. Non, car l'écrivain qui rédige ces vers, peut-être un soir de l'automne 1920, apparaît comme le moi lyrique en train d'évoquer l'étrange veillée funèbre à laquelle il assiste, après la disparition accomplie d'un ancien et fidèle compagnon de route :Vieux peuplier,/ Tu es tombé / Dans le miroir / De l'eau dormante. / Je t'ai vu / sombrer/ Dans le crépuscule / Inclinant ton front / Devant le couchant ${ }^{9}$. Au terme d'un long périple à la fois humain et artistique, débouchant cette fois sur sa lente agonie remémorée, puis relatée en détail, l'heure semble avoir définitivement sonné pour ce représentant par excellence d'une antique complicité artistique de tous les instants, désormais totalement remise en question.

Or dans la perspective de la maladie liée au génie qui, depuis le Problème $X X X$ de la tradition péripatéticienne ${ }^{10}$, met en relation l'âme et le corps dans une perspective hippocratique, le lecteur se retrouve en fait confronté ici à un symbole dont la nature mélancolique et la nuance obscure se doivent d'être plus que jamais retenues. Car, contrairement aux 'álamos', fins peupliers élancés, argentés au point d'en devenir 'bleus'11, et souvent témoins des rêveries expérimentales menées au bord de la rivière par le promeneur, le noir 'chopo' contemplé maintenant dans sa chute sans remède présente, pour sa part, une teinte sombre et des contours dévastés dont la représentation semble plus que jamais inséparable de la nécessité créatrice chargée de s'en faire l'écho lugubre. Celui dont s'élève la voix se retrouve ainsi soudain confronté au spectacle inattendu offert par un arbre appartenant en propre à sa géographie intime, mais qui lui est familier au point d'utiliser l'adjectif 'vieux' pour qualifier d'emblée le patriarche auquel son grand âge avait permis l'acquisition, au sein du bois, d'une expérience ancienne, ainsi qu'en témoigne également la vision de son 'énorme tête

\footnotetext{
9 Livre de Poèmes, "Peuplier mort », op. cit., pp. 80-81. Libro de Poemas, « Chopo muerto » (1920), "Chopo viejo! / Has caído / en el espejo / del remanso dormido, / abatiendo tu frente / ante el Poniente.», OCl, p. 109.

${ }^{10}$ Aristotle, L'Homme de génie et la mélancolie, Problème XXX, traduit du grec par Jackie Pigeaud. Éditeur : Rivages, Paris. Collection : Rivages-Poche, Petite bibliothèque.

${ }_{11}$ Essayant d'éclairer sa lanterne, au milieu de toutes les contradictions qui l'assaillent et sans faire cas de ses échecs successifs, l'auteur s'efforce encore de découvrir partout le mystère de ce «bleu» qu'il sait porter quelque part en lui : couleur onirique et spirituelle qui lui permettra, pense-t-il, de déchiffrer dans un au-delà de lui-même, enfin décrypté, les énigmes qui continuent de lui résister, ou plutôt d'échapper à sa vigilance au niveau du monde extérieur dont il veut capter les secrets. II s'acharne donc sur le papier de fond bientôt bleuté, muni de sa plume elle-même teintée de la nuance céleste, rempli d'une foi certes bien malmenée, mais envahi, dira-t-il, de cet «Azur des cœurs, des forces, / Azur au fond de moi », susceptible de lui ouvrir, peut-être, les portes jusque là interdites : «Je veux lancer mon cri, / sanglottant sur moi-même /.../ En réclamant le bien de l'homme. Amour immense / et bleu comme les peupliers de la rivière.... / Et mon azur à moi, / Pour qu'il remette entre mes mains la grande clé / qui force l'infini. / Sans terreur et sans crainte en face de la mort, / couvert du givre du lyrisme et de l'amour, / Même foudroyé par l'éclair tel un arbre / Et quitte à demeurer sans feuilles et sans un cri». Livre de Poèmes, «Rythme d'automne, 1920, À Manuel Ángeles, I, vv. 121-135, op. cit., p. 103. Libro de Poemas, «Ritmo de otoño », pp. 138-142. «Sobre el paisaje viejo y el hogar humeante / quiero lanzar mi grito, / sollozando de mí como el gusano / deplora su destino. / Pidiendo lo del hombre, Amor inmenso / / y azul como los álamos del río. / Azul de corazones y de fuerza, / el azul de mí mismo, lque me ponga en las manos la gran llave / que fuerce al infinito. / Sin terror y sin miedo ante la muerte, / escarchado de amor y de lirismo, / aunque me hiera el rayo como al árbol / y me quede sin hojas y sin grito.
} 
centenaire'. Mais il ressort d'une connaissance plus large de la vie et de l'oeuvre lorquiennes que le poète est cette fois mis en présence de la disparition redoutée de son arbre emblématique, évocateur d'un paradis depuis longtemps perdu et représentatif d'un difficile cheminement personnel, hors du labyrinthe boisé où le voyageur de l'imaginaire erre maintenant à la manière d'une âme en peine.

Brutalement abattu du haut d'un hier impossible à préciser, le «Peuplier mort» est vu baignant désormais dans une trouble nappe fermée, au calme suspect, qui n'est pas sans rappeler l'environnement corrupteur dont l'auteur des Maladies IV avait dit : «L'eau stagnante transmet la chaleur de couche en couche vers le bas»12. Peut-être était-ce effectivement après une «transmission» de cette nature que l'arbre s'était couché, pour avoir voulu - c'est là une autre hypothèse - passer de l'autre côté du 'miroir' attirant dans lequel, tel Narcisse, il souhaitait se refléter au point de se confondre avec lui, en dépit du risque de s'y retrouver finalement englouti.

Chacun éprouve néanmoins l'impression qu'à partir du constat initialement formulé de cette chute, laquelle coïncide temporellement avec le moment du coucher du soleil, s'ébauche un mouvement lyrique aux lueurs soudain 'crépusculaires'. Sans doute, au départ, les motifs du processus enclenché restent-ils mystérieux, même si l'évocation prend bientôt l'allure d'un écroulement intérieur inéluctable, quand le locuteur déclare : «Ce n'est pas le rauque ouragan / Qui brisa ton tronc, / Ni la lourde hache / Du bûcheron / Qui sait que tu dois / Renaître / C'est ton esprit puissant / Qui a réclamé la mort, / Lorsqu'il s'est vu sans nids, / délaissé / Par les jeunes peupliers $d u$ pré ${ }^{13}$. Toutefois, il faut faire observer que la métaphore symbolisant l'absence d'oiseaux printaniers résonne bientôt de sons amères, quand elle suggère la fuite définitive des représentabnts de la vie ailée hors du possible abri réservé à leur éclosion, une fois passée la saison requise.

Loin de faire appel au seul châtiment climatique olympien possiblement en vigueur, ni à cette autre allégorie traditionnelle de la destruction inexorable en marche que le dramaturge connaît bien et utilisera, par exemple dans la scène de la forêt de «Noces de sang » : «Avant que de sa hache, orme du Douro, / le bûcheron ne t'abatte», le témoin de la chute renvoie le lecteur à une fin programmée. Ne suggère-t-il pas l'idée d'un effondrement orienté vers une fin prévue, puisque fruit d'une volonté délibérée ? Si, quand il est révélé : «Ce n'est pas le rauque ouragan / Qui brisa ton tronc, / Ni la lourde hache / Du bûcheron / Qui sait que tu dois / Renaître / C'est ton esprit puissant / Qui a réclamé la mort, / Lorsqu'il s'est vu sans nids, / délaissé / Par les jeunes peupliers du pré»14. Le noir 'chopo' lentement envahi par une sorte de sève-bile de la même couleur, n'a-t-il pas été finalement vaincu au soir d'un dur combat mené contre sa propre tristesse suicidaire? ${ }^{15}$.

A la différence d'autres textes contemporains de celui-ci, la destruction de la silhouette végétale familière est dès lors présentée comme la conséquence inévitable

\footnotetext{
${ }_{12}$ D'après Hippocrate, Nature de l'Enfant et Maladies $I$, édit. de R. Joly, Paris, Belles-Lettres,1970. Jackie Pigeaud, Une physiologie de l'inspiration poétique. De l'humeur au trope, in Les Etudes Classiques, tome XLVI, n¹, 1918, pp. 23-31. Jackie Pigeaud, op. cit., note 381, p. 321. Maladies IV, op. cit., 25, 5.

${ }_{13} \mathrm{Ibid}$, vers 7-12. Ibid. pour la version en Espagnol : . « No fue el vendaval ronco / el que rompió tu tronco, / ni fue el hachazo grave / del leñador, que sabe / has de volver / a nacer. / Fue tu espíritu fuerte / el que llamó a la muerte, / al hallarse sin nidos, olvidado / de los chopos infantes del prado. / Fue que estabas sediento / de pensamiento, / y tu enorme cabeza centenaria, / solitaria, / escuchaba los lejanos / cantos de tus hermanos ", op. cit., p. 109.

14 Ibid, vers 7-12. Ibid.

15 Ibid. Ibid.
} 
d'un désespoir sans remède, lequel avait peu à peu gagné cet esprit fort' ${ }^{16}$ au point de le plonger dans un abattement duquel n'émergeait plus que son désir de mort ${ }^{17}$. Car il ressort des vers rédigés cette fois, que la solitude absolue résultant du dialogue interrompu avec l'arbre axial de l'éden de jadis, était devenue la cause invisible d'un appel pressant lancé en faveur d'une solution extrême : "C'est que tu étais assoiffé / De pensées / Et que ton énorme tête centenaire/ Solitaire / Epiait les lointaines / Chansons de tes frères „18. Aussi bien, cette même puissance manifestée sous la forme d'un élan par trop immodéré, rappelle également le langage de Chrysippe et la référence métaphorique faite à la course, qui permettait au Stoïcisme d'établir une utile, bien que difficile comparaison analogique, en expliquant :

«Je pense qu'il y a quelque chose de très voisin pour les élans de l'âme, aussi, parce qu'ils excèdent le rapport logique, de sorte que, lorsqu'on s'élance, on n'est pas docile à l'égard de la raison. Car il y a rapport de l'élan naturel selon la raison, d'une part en ce qui concerne la distance, d'autre part en ce qui concerne la valeur. C'est pourquoi l'élan débordant de ce qui excède ainsi est dit mouvement de l'âme contre nature et non raisonnable ${ }^{19}$.

Autodestruction volontaire, donc, plutôt que sacrifice imposé de l'extérieur par quelque divinité vengeresse; et solution de toute façon déraisonnable, seulement justifiée en la circonstance à partir du sentiment intérieurement éprouvé par l'arbre lui-même d'une inutilité coupable. Solution socratique, en ce sens également, du Maître dans l'erreur, ou non reconnu comme tel face à ses disciples. Car une telle décision suppose certainement la prise de conscience désespérée d'une nécessité de découverte de soi passant par le regard d'autrui, le sujet en cause vivant parmi un grand nombre d'autres. Or cet être ainsi doté de son libre arbitre, qui sera-t-il? Quelqu'un pour qui l'on n'éprouvera ni tendresse ni haine, en outre initialement estimé de la rumeur publique. Un vieillard unanimement reconnu comme un sage serait un bon choix, répond alors l'auteur du traité Des Passions ${ }^{20}$, estimant qu'Apollon avait raison qui exigeait que l'on se connût soi-même de la sorte. Or, la sensation d'échec guettait précisément ce pédagogue d'âge respectable, à ses yeux désavoué par les jeunes générations («chopos infantes») qui l'avaient soudain délaissé, en négligeant son enseignement ancestral humaniste, qualifié de fraternel.

II est alors difficile de ne pas repenser sur ce point aux lignes extraites du livre du Professeur Jackie Pigeaud, venues souligner la nécessité de la relation sociale développé par Galien, comme dans la Lettre 52 de Sénèque, quand il est expliqué par exemple : «Le philosophe distingue trois catégories d'individus : ceux qui peuvent aller à la vérité sans aide, par exemple Epicure; ceux qui ont besoin d'aide; c'est le cas de Métrodore; et ceux, enfin, qui ont besoin d'un moniteur et d'un dresseur (quibus

\footnotetext{
${ }^{16}$ Ibid Ibid.

17 Ibid Ibid. pour la version en Espagnol.

18 "Chopo muerto», Ibid, vers 13-22.

19 Jackie Pigeaud. La Maladie de l'âme : étude sur la relation de l'âme et du corps dans la tradition médicophilosophique antique, thèse de doctorat, publiée en 1981 ; réimpr. avec une nouvelle préface, Paris, Les Belles Lettres, 2006, 590 p. La maladie de l'âme, «Stoïcisme et maladie de l'âme», "Chrysippe et l'analogie de la course», op. cit., pp. 268-269.

${ }^{20}$ Galien explique par exemple : "C'est aux autres de faire le diagnostic de ce que nous sommes, pas à nousmêmes", Des Passions de l'âme et de ses erreurs, trad., et comment., de R. van der Elst, Paris, Delagrave, 1914 , t. I.
} 
non duce tantum opus sit, sed adiutore et, ut ita dicam, coactore)» ${ }^{21}$. Et l'auteur du livre-thèse cité d'ajouter alors ce commentaire comparatif : «Galien ne conçoit pas qu'il puisse y avoir d'autre relation pédagogique que de moniteur à élève. L'on peut dire que le médecin s'arrête où le philosophe commence; ou encore qu'ils ont un niveau en commun qui représente le dernier niveau pour le médecin, le premier pour le philosophe dans la relation pédagogique»22.

Le fait est que l'impression désolée, ressentie face au passage musico-poétique suggéré dans le poème, paraît aller dans le sens d'un tel discours, quand l'appel de mort intérieur - lequel précède le mouvement menant à la mort tout court - suppose un échec total en ce domaine dit 'relationnel'. Et sur ce point, l'on ne saurait oublier d'envisager les vers :»Epiait les lointaines/ Chansons de tes frères» sous l'angle, également analysé par Jean Starobinski ${ }^{23}$, de la dissonance existant entre l'homme mélancolique et la musique du monde. Ici, en effet, la discordance irréductible devient manifeste quand s'est creusée, avec la distance, l'infranchissable frontière séparant l'être-arbre de ses semblables aussi bien sur le plan physique que spirituel; à l'heure où celui qui était chargé d'une mission de nature culturelle auprès de ses jeunes congénères sait qu'il ne peut plus la remplir : et c'est alors le musicien-poète qui parle par la bouche de ce double de lui-même qui ne reçoit ni ne renvoie plus les échos mélodieux ou les notes harmonieuses des 'coplas' traditionnelles dans l'air crépusculaire.

Car il est encore une cause supplémentaire au désespoir du visiteur du soir, lequel pose sur le «Peuplier mort» son regard sibyllin chargé d'y rechercher de manière postume chacun des signes cliniques du mal susceptible d'avoir causé sa perte ${ }^{24}$; quand le locuteur ajoute : «En toi tu conservais / Les laves / De la passion, / En ton coeur / La stérile semence / de Pégase. / La terrible graine / D’un amour innocent / Pour le soleil couchant» ${ }^{25}$. Or, la métaphore n'est-elle pas par excellence, comme il a été dit et démontré, le trope du mélancolique ${ }^{26}$ ? En ce sens, tandis que les coulées refroidies de matière liquide suggèrent le feu, maintenant éteint, d'un volcan souterrain incapable à l'avenir d'une nouvelle éruption, le sentiment sous-jacent qui jaillissait naguère impulsivement de l'écorce en fusion vient rappeler au lecteur l'échec d'un conflit larvé de l'Éros débouchant bientôt sur l'appel de Thanatos. Quelle solution trouver, en effet, face à l'autre combat sans merci hier mené contre la chair, alors que la conquête d'une hypothétique pureté crépusculaire en était, semble-t-il, l'enjeu vital inaccessible? ${ }^{27}$. L'arbre définitivement mutilé se comporte en fait exactement comme

\footnotetext{
${ }^{21}$ Jackie Pigeaud, op. cit., p. 69, note 173. Cf. Sénèque, Ep. 52, 4.

22 Jackie Pigeaud, La maladie de l'âme, ibid. La suite de la citation dit : [...] L'on voit que la médecine ancienne s'est interessée au problème de la relation de l'âme et du corps et que la question du monisme et du dualisme lui est essentielle», id., pp. 69-70.

${ }^{23}$ Jean Starobinski, Histoire du traitement de la mélancolie des origines à 1900, Bâle, Geigy, 1962, pp. 35sq.

${ }^{24}$ Car le peuplier reste à la fois l'aïeul ancestral susceptible de guider les pas du petit fils sur le sentier de l'existence, et le «maître» capable d'enseigner sa leçon à l'écolier, au sein du pré. L'arbre des confidences de jadis, n'est-il pas à la fois possesseur d'une science ancestrale à transmettre à autrui, et chargé d'une véritable mission éducatrice auprès de ses jeunes disciples? Ce mentor à l'âme autrefois musicale s'est donc retrouvé bien seul, en se découvrant soudain "sans nids» - c'est-à-dire sans oiseaux capables de s'envoler depuis l'échafaudage de ses branchages -, puis plus tard plongé dans un profond désespoir, à la suite de la prise de conscience de la négation de son très ancien rôle culturel.

${ }^{25}$ Ibid., vers . «En tu cuerpo guardabas / las lavas / de tu pasión, / y en tu corazón, / el semen sin futuro de Pegaso. / La terrible simiente / de un amor inocente / por el sol de ocaso".

${ }^{26}$ Cf. Jackie Pigeaud, Une physiologie de l'inspiration poétique. De l'humeur au trope, op. cit., pp. 23-31. Cf aussi, le chapitre III de La Maladie de l'âme : «Stoïcisme et maladie de l'âme», op. cit., pp. 243-371.

27 L'allusion à «la semence» stérile et sans avenir du Pégase mythique évoque aussi bien la genèse fortement compromise d'un art qui aurait perdu ses ailes, que la source maintenant tarie d'une hypothétique procréation
} 
I'homme, au moment d'effectuer cet autre saut métaphoriquement exprimé qui faisait déjà dire à Sénèque, à propos De la colère il est vrai : «Certaines choses au début sont en notre pouvoir, plus tard leur force nous entraîne et ne nous permet plus de rétrograder. L'homme précipité dans un abîme n'est plus maître de ses mouvements, et il ne peut ni arrêter ni retarder sa chute» ${ }^{28}$. Une telle déclaration nous semble pourtant valoir également dans le cas qui nous concerne ici.

Car la comparaison avec le personnage mythique s'impose d'autant plus à présent, que chacun a encore en mémoire la vision des anciennes blessures de ce Bellérophon en quête des solitudes dont les vers lorquiens semblent se faire l'écho; quand, à la lueur du Problème XXX, il était montré par Homère en train de parcourir les plaines Aleïon, sous l'effet des ravages d'une montée bilieuse qui lui faisait dévorer son propre coeur et éviter la rencontre des humains ${ }^{29}$. Après tant d'autres, ce «peuplier-héros» malheureux du texte a en fait lui-même impulsé un mouvement passionnel vers le bas, après avoir préféré l'appel terrestre de «l'eau dormante» à l'élan céleste du cheval volant toujours capable de faire jaillir quelque courant ailé, si l'on en croit la relation légendaire qu'il entretient avec l'eau vive.

À ce stade, l'impossibilité de se dominer soi-même, pour l'arbre comme pour l'être lyrique obligé de le contempler dans sa chute icarienne, vient renouer de manière originale avec l'antique définition stoïcienne des passions envisagées, aussi bien comme des maladies de l'âme, que dans leur rapport analogique avec les maladies du corps. Surtout, quand l'impossible fécondité suggérée dans les vers cités plus haut a elle-même pour siège, dans le passé végétal, un centre 'cordial' que le locuteur situe à la confluence d'une souffrance atteignant l'affectivité blessée et d'une douleur biologique venue éprouver les forces vives du végétal miné en profondeur. Dans le cadre de l'évolution de l'écriture lorquienne, se fait ainsi jour une expression métaphorique complexe, destinée à caractériser des affections valant à plusieurs niveau, aussi bien pour le 'peuplier noir' que pour l'homme : à son image physique-

sans lendemain. En ce qui concerne la relation à l'orage, cf. Hésiode, Les Travaux et les jours, Le Bouclier, trad. par P. Mazon, Paris, Belles Lettres 1928, Pégase y est vu «portant le tonnerre et la foudre pour le compte du prudent Zeus», p. 42. Mais sans doute convient-il aussi de remarquer et de faire observer que le "coeur» est ici une fois encore directement concerné par l'échec. Ainsi, quand à la difficulté d'une créativité d'ordre spirituel favorisée par le galop, désormais ralenti du coursier ailé de jadis, vient s'ajouter l'impossible réalisation d'un rêve de pureté, jamais vraiment concrétisé ni concrétisable dans le cadre d'une saine complicité avec le coucher du soleil.

Cf. aussi les vers : «J'aimerais dans ce livre», p.115 : «J'aimerais laisser dans ce livre / toute mon âme.../ On y voit un homme nu / sur Pégase sans ailes..». En ce qui concerne différentes visions du cheval ailé voir encore : «Ballade triste» ou «Petit poème», Grenade, avril 1918, p. 23 (« Balada triste », "Pequeño poema », abril de 1918, Granada, pp. 27-28) ; «Le Pressentiment», août 1920, Vega de Zujaira, p.41 («El Presentimiento », agosto de 1920, Vega de Zujaira, pp. 54-55); «Cocotte en papier», juillet 1920, p. 58 («Pajarita de papel », julio de 1920, pp. 76-77).

En dehors du mythe de Pégase, il est utile de rappeler la relation qui s'établissait, dans l'Antiquité, entre le cheval ailé et l'eau (ainsi qu'avec l'orage). Ceci permet de suivre ici le fil lorquien du thème, quand le poète voit "les moustiques» comme des «pégases de la rosée» ("pegasos del rocío »), («Le soleil s'est couché», août 1920, p. 56) ; «Se ha puesto el sol », agosto de 1920, p. 75) ; ou quand il fait ici symboliquement du cheval volant, à tous les sens du terme, le contraire d'un nuage porteur de gouttes fécondes. Ni la créativité, ni l'amour, ni la spiritualité, ne s'abreuvent plus à cette source ailée. Dès lors, l'imagination faiblit et n'est plus sublimée ; l'inspiration est menacée ; l'impétuosité des désirs n'est plus alimentée, et l'homme n'est plus protégé du danger de pervertissement. La source est à présent «miroir de l'eau dormante» qui accueille le «héros des bois / sans ramages", tandis que la chute de Pégase succède à l'élévation antérieure et que la stérilité remplace la fécondité première. (Cf. P. Diel, Le symbolisme dans la mythologie grecque, préf. de G. Bachelard, Paris, 1952, 1966). 11

${ }^{28}$ Idem, I. 7. 4., traduction Bourgery.

${ }^{29}$ Problème XXX, 953 a, t. 2, p. 318. 
ment, moralement, psychologiquement, spirituellement attaqué, puis abattu, lors de la perte de ses illusions peu à peu battues en brèche.

Curieusement, l'auteur de ces strophes donne l'impression de se faire à sa manière originale l'écho littéraire renouvelé de la controverse ardue qui avait autrefois tant divisé médecins et philosophes, à propos du siège de l'âme rationnelle. Ainsi, par exemple, quand Chrysippe, au grand dam de Galien, oubliait l'autorité de Platon pour affirmer que l'hégémonie est dans le «coeur»:

«ll me semble, dit Chrysippe (a), que le plus grand nombre est porté à cette affirmation, comme si les gens sentaient tous que les passions où la pensée est impliquée naissent dans la région du thorax, surtout dans la région où le coeur est situé, en particulier les chagrins, la colère, et surtout le désir, qui monte comme une vapeur et se répand au dehors (b) et envahit le visage et les mains, et devient pour nous notre apparence». ${ }^{30}$

Et quand Sénèque expliquait, dans le De ira : «L'esprit n'a pas de siège à part, et il n'observe pas de l'extérieur les passions pour ne pas les laisser avancer au-delà du point qu'il convient, mais il se change lui-même en passion et pour cette raison ne peut appeler à son secours cette force utile et salutaire déjà trahie et affaiblie». ${ }^{31}$

Il convient néanmoins de faire observer que la voix poématique lorquienne fournit une réponse dualiste au problème résolu en termes de monisme, chez les deux auteurs cités. Car, si l'approche faite du «Chopo muerto» propose ici au lecteur une variante originale du thème ancien de la folie du sage, il résout la question en montrant que l'impossibilité pour l'arbre désespéré de 'se vaincre soi-même', après une lutte farouche entre forces antagoniques, prend une signification duelle du fait qu'il existe un point de vue où 'la force de l'esprit' peut se regarder dans sa confrontation à la 'passion du corps'. II se produit ainsi une conversion, une altération, une aliénation menant le sujet capable de 'pensée' au point de non retour susceptible de susciter sa chute finale, sous l'action d'une contamination de la maladie du corps sur celle de l'âme, ou inversement, selon le principe de l'interaction. À l'arrivée de cet étonnant mouvement poético-philosophique, est alors poussée l'exclamation traduisant l'impuissance éprouvée face aux conséquences d'une expérience 'amère' comme la bile, capable de s'infiltrer à la manière d'un âcre poison dans les ramures ou les veines, jusqu'à modifier le décor qui entoure l'arbre ainsi que son spectateur : «Quelle amère et profonde désolation / Pour le paysage / Que le héros des bois / Sans frondaisons! ’32

Après tant d'autres, ce «peuplier-héros» a donc impulsé son propre élan destructeur vers le bas, après avoir préféré la noyade terrestre dans 'l'eau dormante' à l'appel céleste du cheval volant capable de faire jaillir quelque courant ailé, en fonction de la relation légendaire qu'il entretient avec la vive fontaine et la rosée des nuées. De sorte

\footnotetext{
${ }^{30}$ Et quand le même Chrysippe raisonnait en des termes que critiquait l'auteur de la Maladie sacrée 17 : «Le coeur, dont certains disent qu'il est le centre de la pensée et que nous éprouvons par lui chagrin et souci»; alors qu'à l'inverse, les médecins antiques estimaient pour leur part que l'on sent par où l'on pense. Cf. Jackie Pigeaud, La Maladie de l'âme : «Stoïcisme et maladie de l'âme», op. cit., p. 379. Pour les références (a), cf. note 18, ibid; (b), 19, ibid;

${ }^{31}$ Sénèque, De ira, I. 8. 2, cité id., p. 317.

32 Idem, vv. 31-34. La traduction de la Pléiade ne rend pas compte ici de l'expression "amargura tan honda", évocatrice d'une «profonde « «amertume» ou «aigreur», âcre comme la bile noire en train d'envahir de l'intérieur la totalité du «paysage» poétique lorquien : "Qué amargura tan honda / para el paisaje, / el héroe de la fronda sin ramaje! », ibid. .
} 
qu'au lieu de renouer avec le pégé - dont le nom rappelle précisément le coursier né aux sources de l'Océan et qui avait été trouvé par Bellérophon buvant à celle appelée Pirène -, l'arbre-Pégase lorquien sera au contraire englouti, puis entraîné dans une ultime course mortelle par l'onde venue lui servir finalement de glauque tombeau aquatique : «Tu auras pour cheveux verts / Les orties / Et un jour le courant / Souriant / Emportera ton écorce / Tristement. » Au préalable, une fois rappelés les motifs secrets de cette silencieuse mise à mal, partagée dans une solitude à deux, le moi lyrique prend des accents oraculaires pour évoquer, au futur, les étapes successives du destin tragique désormais réservé au végétal. Nous entendons alors le locuteur se faire le porte-parole de l'inéluctable : «Tu ne seras plus le berceau / De la lune, / Ni le rire magique / De la brise, / Ni la canne d'un astre / Chevalier, / Tu n'auras plus de printemps / En ta vie,/ Tu ne verras pas les semailles / Refleurir. / Tu seras le gîte des grenouilles / Et des fourmis»33. D'un côté, le lecteur découvre que le peuplier lorquien est devenu le double vaincu auquel s'adressait jadis le message de Sénèque, par l'intermédiaire de la figure en usage pour la passion à l'origine de la mélancolie : «Mais le fait de se jeter sans qu'on puisse revenir la-dessus, supprime toute délibération et regret, et il ne peut pas ne pas parvenir là où il aurait pu ne pas aller... „34. De l'autre, il constate qu'à l'énergie céleste s'est substituée une activité circulant dans les entrailles de la terre ; $œ u v r e$ des lunaires intercesseurs croassantes de la pluie dans lesquelles la civilisation égyptienne voyait quant à elle les forces obscures d'un monde encore inorganique ..., ou les «créatures spontanées des eaux primordiales à côté des grouillantes habitantes souterraines des souches en voie de pourrissement.

Mais la clé du texte qui assimile partout l'arbre et l'homme réside dans la dernière strophe, laquelle confère à l'ensemble de cette composition son véritable éclairage tragique, quand est enfin glissé l'aveu : «Vieux peuplier, / Tu es tombé / Dans le miroir / De l'eau dormante. / Je t'ai vu sombrer / Dans le crépuscule / Et j'écris pour toi cette élégie (a) / Qui est aussi la mienne ${ }^{35}$ Car l'assimilation progressive entre la première personne poétique et son interlocuteur végétal y devient effective, grâce à la confession de l'existence d'une véritable symbiose des deux êtres lyriques, simultanément accablés d'un mal identique. L'un et l'autre ne sont-ils pas finalement réunis par une même souffrance physique, affective, mentale, au sein d'un destin funeste commun venu les imprégner tous deux du désir passionnel de mettre fin à leurs jours ? Et dès lors qu'un devenir fatal concerne aussi bien l'homme que le 'chopo' de son jardin secret, il est certain que toutes les visions imagées qui précèdent résonnent doublement d'une signification analogique, à la lueur des derniers vers ${ }^{36}$.

\footnotetext{
${ }_{33}$ «Peuplier mort », "Chopo muerto » : "Ya no serás la cuna / de la luna, : ni la mágica risa / de la brisa, / ni el bastón de un lucero / caballero. / No tornará la primavera / de tu vida, / ni verás la sementera / florecida. / Serás nidal de ranas : y de hormigas./Tendrás por verdes canas / las ortigas, / y un día la corriente / llevará tu corteza / con tristeza ", ibid, ibid.

${ }^{34}$ Ibid. ibid. Cf. à ce sujet les métaphores «de la pierre et du saut de Leucate».

${ }^{35}$ [plainte) dit de manière inexacte la traduction de la Pléiade, op. cit., p. 81. «Yo te vi descender / en el atardecer / y escribo tu elegía, / que es la mía", op. cit., p. 109.

${ }^{36}$ Une fois accomplie la chute du peuplier et du poète, brisé avec lui, c'est pour celui-ci que commence véritablement le drame, son propre drame présent et futur : c'est «sa» passion qui semble s'éteindre à jamais, "son» idéal qui, frustré, l'abandonne pour toujours, «son» innocence qui est compromise, tandis qu'il ressent comme coupable la relation qu'il entretient désormais avec le soir qui tombe. Et l'on peut se demander, étant donné le registre de vocabulaire utilisé, si le sentiment amoureux exprimé dans ces vers ne reste pas pour toujours frappé de quelque obscure malédiction. Car tandis qu'il présente initialement un aspect aussi illusoire et dangereux que non procréateur («stérile semence «, ou «terrible graine «), il n'a en outre pour seul lendemain que «le soleil couchant» dans lequel il se meurt maintenant.
} 
C'est donc véritablement la mort dans l'âme que le moi 'élégiaque', reflet fidèle de l'affligeant spectacle qu'il a dorénavant devant les yeux, exprime au bout du compte la sombre peine éprouvée de manière unique en son genre, dans les vers venus clore le poème à la manière d'une plainte douloureuse. Car, à ce dernier stade des manifestations dévastatrices d'une affection mettant en relation l'âme et le corps - et dont le Problème XXX de la tradition péripatéticienne fait traditionnellement celle du génie créateur -, la maladie d'amour-mélancolie d'absence du poète de Grenade suit un chemin artistique conduisant «de l'humeur au trope», au terme duquel l'artiste renoue à travers son langage propre, avec l'arbre métaphorique de l'impossible espoir.

\section{De l'expérience juvénile de «la porte étroite» (1916-1917) à son écho chez le cor- respondant, (1924) : «Federico-arbre » supplicié.}

Un soir d'août 1924, soit quelques huit ans après ses deux visites à Burgos ${ }^{37} \mathrm{com}^{-}$ me étudiant de l'Université, le poète passe l'été à Grenade, d'où il écrit à ses amis. Or, dans une lettre adressée à Melchor Fernández Almagro, il va soudain interroger son destinataire en ces termes : «Te ha gustado Burgos»38 Après quoi, il se laissera aller à l'afflux des émotions qui continuent apparemment à l'envahir, dès qu'il prononce le nom de cette cité : «Qué dulce recuerdo, lleno de verdad y de lágrimas me sobrecoge cuando pienso en Burgos... ¿ Te choca ? Yo estoy nutrido de Burgos, porque las grises torres de aire y plata de la catedral me enseñaron la puerta estrecha por donde yo había de pasar para conocerme y conocer mi alma $>^{39}$. La 'porte étroite' dont il est question dans cette missive et sur laquelle nous ne nous attarderons pas ici, rappelle bien sûr la phrase de saint Matthieu : «Entrez par la porte étroite, parce que large est la porte et spacieux le sentier qui conduit à la perdition; et ils sont nombreux, ceux qui

37 II faut se souvenir, en effet, que le lecteur retrouvera là l'étudiant García Lorca, au cours d'une série d'excursions universitaires organisées à travers l'Espagne entre le 8 juin 1916 et le 7 août 1917 par son maître Martín Dominguez Berrueta, «professeur de Théorie des Arts et de la Littérature à l'Université de Grenade ». Effectuées sous la houlette de l'actif pédagogue soucieux de confronter ses disciples de l'université à la réalité concrète des sites, des monuments, ainsi que des hommes de l'histoire et de la vie, de telles expériences allaient donc conduire successivement le jeune García Lorca, en compagnie d'autres camarades sélectionnés parmi les meilleurs étudiants, d'abord en Andalousie, à Baeza, Ubeda, Córdoba, Ronda (Du 8 juin au 16 juin 1916.); puis à Madrid, El Escorial, Avila, Salamanca, Santiago de Compostela, La Coruña, Lugo, León, Burgos Segovia (Du 15 octobre au 8 novembre 1916); ensuite, une seconde fois à Baeza (Fin mai à début juin 1917) ; enfin, à Madrid, Palencia, « sans tenir compte d'un séjour d'un mois à Burgos », avec l'exploration de tous ses environs : -Fresdelval / - San Pedro de Cardeña / -Real Monasterio de las Huelgas / -Santo Domingo de Silos / Covarrubias / -San Pedro de Arlanza / -Cartuja de Miraflores (Du 15 juin au 7 août 1917), le dernier itinéraire mentionné ayant eu lieu «pour les seuls Lorca et Berrueta ». Cf. Michèle Ramond, Le passage à l'écriture,. Le premier livre de Lorca, Toulouse, Presses Universitaires du Mirail, Collection «Hespérides», 1989. pp. 24-25.

${ }^{38}$ Carta A Melchor Fernández Almagro, [Asquerosa, ¿finales, de julio-agosto, 1924], in Epistolario, op. cit., pp. 237-238. «As-tu aimé Burgos ? », interroge le correspondant dans une lettre à Melchor Fernández Almagro, in Correspondance, Grenade, août 1924, La Pléiade, I, pp. 1034-35.

39 Carta A Melchor Fernández Almagro (17), Trad. in Correspondance, Grenade, août 1924. op. cit., p. 1034 : Quel doux souvenir me saisit, plein de vérité et de larmes, lorsque je pense à Burgos... Cela te surprend? Je suis nourri de Burgos : les tours grises d'air et d'argent de la cathédrale m'ont montré la porte étroite par où je devais passer pour me connaître et pour connaître mon âme «. Dans un poème sans date (1918?), G. Lorca écrit ces vers, également significatifs, que nous traduisons ici, après les avoir utilisés en exergue, à propos de l'étude relative à Doña Rosita :»Une porte / n'est une porte / que lorsqu'un mort / est passé par elle./ Rose à deux pétales / que l'air ouvre et referme», «Une porte», En Marge du Livre de Poèmes, p. 125. Cette déclaration paraît renouer avec la porte symbolisant le lieu de passage entre le connu et l'inconnu, la lumière et les ténèbres. Souvent, la porte ouvre sur un autre monde (celui d'une mort réelle ou symbolique) et invite l'homme à franchir un seuil du domaine prophane au domaine sacré. C'est une incitation à un voyage vers l'au-delà. C'est aussi un intermédiaire initiatique conduisant vers différents «mystères» et susceptible de conduire l'être vers une transcendance qui n'appartient qu'à lui.. 
s'y engagent. Mais elle est étroite, la porte, il est resseré le chemin qui conduit à la vie; et ils sont peu nombreux ceux qui le trouvent ${ }^{40}$; et elle symbolise plus que jamais le lieu de passage entre deux états et l'ouverture sur un mystère, présentant à travers ces lignes une valeur psychologique et dynamique très particulière. En effet, non seulement elle semble avoir indiqué à celui qui le cherchait, le chemin vers la lumière à partir des ténèbres, mais encore elle l'a invité à franchir le seuil à caractère initiatique et à suivre la voie tracée de l'autre côté. Une telle ouverture ne constitue-t-elle pas une invitation au voyage vers un au-delà? Mais lequel dans le cas présent?

En réalité, le correspondant ne le dit pas. Simplement, il fait appel à l'évocation des 'tours grises d'air et d'argent' d'une 'connaissance' personnelle de nature spirituelle. Et ce connais-toi toi-même aux couleurs et à la forme d'une révélation aérienne unique en son genre, auquel García Lorca affirme avoir accédé durant son excursion à la cathédrale de Burgos, constitue dit-il, pour lui, une véritable 'nourriture' qui continue à l'alimenter chaque jour, des années après en avoir fait l'expérience privilégiée. Or, une chose frappe aussitôt le lecteur de ces lignes : à savoir que le passage du domaine profane au domaine sacré auquel invite ici une perspective à l'écho quelque peu babélique pour l'écrivain (la tour de Babel, porte du ciel et de Dieu, mais aussi clé de son langage futur) et qui serait dans cette perspective, susceptible d'unir les trois mondes (ciel, terre, univers souterrain), passe curieusement par l'arbre qui sert également partout de clef de voûte à l'édifice physique, affectif, spirituel, et artistique lorquien. Mais cet arbre lui-même n'est-il pas, d'un point de vue symbolique, l'expression imagée des rapports qui s'établissent entre les trois niveaux du Cosmos, lui qui entre en relation avec le domaine d'en-dessous, par l'intermédiaire de ses racines fouillant les profondeurs où elles s'enfoncent, avec la surface, par son tronc directement au contact du sol et les premières branches qui y sont reliées, avec les sphères éthérées, grâce à ses ramures supérieures et à sa cîme, attirées vers le haut sous l'effet de la lumière du ciel?

Voici, en effet, qu'intervient sans plus tarder, dans la lettre, la mention des peupliers obsédants, éléments végétaux certes intégrés à la nature environnante, dans cette circonstance précise, mais dont le rôle n'est pas seulement de caractériser un décor, puisqu'ils se font soudain l'écho d'une imagerie très propre au poète. II est certain qu'une telle référence apparaît désormais à ses yeux aussi inséparable de l'évocation des monuments visités, que de l'expérience personnelle acquise à cette occasion, lorsque l'auteur s'exclame : « iQué verdes chopos! Qué viejo viento! !Ay, torre de Gamonal y sepulcro de San Amaro! Y iay, mi niño corazón !... Mi corazón como nunca estará de vivo, lleno de dolor y gracia eterna ${ }^{41}$. Si la relation avec

\footnotetext{
${ }^{40}$ La symbolique chrétienne de la porte s'est inspirée de la déclaration de Jésus rapportée par l'Evangile selon saint Jean $(X, 9)$ : «Je suis la porte : si quelqu'un entre par moi, il sera sauvé...». C'est pourquoi le Christ en gloire surmonte généralement la porte centrale des cathédrales, cependant que les portes des églises représentent souvent, sous la forme de sculptures, les vertus chrétiennes en lutte avec les péchés. L'archange Michel et l'apôtre Pierre, muni des clés, sont ainsi les gardiens des Portes célestes. En ce qui concerne la «porte étroite", elle constitue l'une des deux voies dont parle saint Matthieu, dans Le Discours sur la Montagne, 7, 1314. Le thème est classique. On le trouve même chez les moralistes païens, et à plusieurs reprises dans l'Ancien Testament, notamment dans le Deutéronome, par ex., 11, 26-28; 30, 1, 15-20; ces textes opposent le chemin de la vie, lequel est droit et lumineux, et le chemin de la mort, qui est tortueux et obscur. II semble que l'étroitesse de la porte et du sentier menant à la vie ne soient pas soulignés avant l'Evangile (ici et dans saint Luc, 13, 2324). Il s'agit d'une loi propre au christianisme : «Si le grain ne meurt, il reste seul» (Jean, 12, 24) : «il nous faut passer par bien des épreuves pour entrer dans le royaume de Dieu» (Ac. 14, 20).

${ }^{41}$ Correspondance, Grenade, août 1924, op. cit., p. 1034. Le texte dit : Quels peupliers verts! Quelle brise ancienne! Ah, tour de Gamonal et sépulcre de San Amaro! ah, mon coeur enfant!... Mon coeur comme je ne
} 
l'univers affectif inséparable de l'existence du petit garçon d'autrefois s'établit ici une fois encore, dans toute sa force et son évidence, elle apparaît aussi dans sa grande complexité symbolique inconsciente. Les peupliers contemplés lors de l'excursion dans la région de Burgos ${ }^{42}$ ne reverdissent-ils pas subitement, comme ressourcés à quelque onde vivifiante et printanière qui vient les colorer d'une espérance neuve? Le souffle de la brise éccouté au passage ne vient-il pas résonner brusquement d'un autre son déjà entendu, des années plus tôt, par celui qui possédait un don de communication unique avec le monde naturel qui l'entourait alors? Tandis qu'un étrange processus de transformation s'effectue à cette occasion.

D'un côté, la teinte 'verte' redevient en un instant celle des arbres du patio de l'enfance heureuse et libre, ainsi que la nuance d'un imaginaire en proie à toutes les fantaisies, ou capable de toutes les métamorphoses ; de l'autre, l'aspect 'ancien' du vent suggère la réapparition nostalgique, dans la mémoire affective de l'homme de vingt-six ans, d'années de bonheur autrefois connues bien que lointaines, grâce à la possibilité d'un antique souffle traditionnel et culturel régénérateur ${ }^{43}$. II ressort néanmoins des aveux de ce courrier que la manifestation mystérieuse dont il est question dans ces lignes a modifié le cours de l'existence lorquienne et représenté une véritable épreuve, comme en témoigne la phrase : «Quel doux souvenir me saisit, plein de vérité et de larmes, lorsque je pense à Burgos... $»^{44}$. En fait, ce qui fait la grande originalité de la manifestation à laquelle il est fait allusion en la circonstance, est qu'elle semble s'expliquer à son tour depuis le regard porté, un regard définitivement marqué par l'antique perception à la fois colorée et musicale des «peupliers» de l'enfance andalouse : arbres vus et écoutés dans un passé très lointain et qui avaient à jamais marqués la sensibilité poétique. C'est du moins là ce que laisse entendre l'exclamation « iay, mi niño corazón » (dont la traduction «ah, mon coeur enfant » ne rend qu'imparfaitement le sens profond, en Français), au moment même où l'auteur se retrouve, non seulement spirituellement, mais surtout affectivement, tel qu'il était dans cet hier béni et joyeux de sa courte existence où il pouvait à loisir écouter le bruit «ancien » du vent dans les peupliers qui prononçaient son prénom en lui parlant un langage propre, compris de lui seul. De sorte qu'une telle bouffée d'air pur et qu'un tel bain de jouvence donnent l'impression de renvoyer doublement au passé : celui de la visite inoubliable de Burgos et de ses environs, au cours de l'année 1917, d'abord; celui des jeux en compagnie des

\footnotetext{
l'aurai jamais plus, plein de douleur et de grâce éternelle ".

42 Pour les dates signalées, nous renvoyons le lecteur au travail de Michèle Ramond, Le Passage à l'Ecriture, «Prélude et Fugue», op. cit., p.p. 9-20; «l'âme du Livre», op. cit., pp. 23-51.

${ }^{43}$ En ce sens, l'importance revêtue par le souvenir des peupliers castillans dans un autre courrier expédié de Grenade, sans doute en août 1924, n'est-elle pas à négliger, puisqu'elle est pour l'auteur l'occasion d'autres retrouvailles authentiques avec lui-même, à travers des jalons ainsi semés sur son passage ; au fil d'étapes qui le renvoient simultanément aux arbres contemplés à diverses époques de sa vie et, au-delà, à ceux du jardin de son passé le plus précieux, lequel devait le poursuivre jusqu'à la fin de sa vie, à travers ses divers déplacements, y compris sur le continent américain. soit durant l'été 1917.

A ce stade, la référence au paysage est non seulement double ou triple (par le biais du renvoi aux visites de la ville à l'automne 1916, peut-être à l'été 1917, et de toute manière à l'enfance), mais encore extérieure et intérieure, au moment où l'évocation des monuments ainsi découverts, ainsi que l'expérience spirituelle de la porte étroite acquise à cette occasion, permettent chez l'auteur l'illusion fugitive de la réapparition du paradis perdu de l'enfance heureuse, avec son décor privilégié, jadis aimé et connu.

${ }^{44}$ En réalité, si une telle invitation au voyage intérieur passe initialement -et inévitablement- par une prise de conscience lucide d'une authenticité (appelée «verdad»), elle suppose en outre une démarche douloureuse, lourde de chagrin («lágrimas»). II n'en est aussi pour preuve que l'autre constatation citée, relative au «coeur». A nouveau, le progrès en direction d'un approfondissement de la «connaissance» et de la «vie» est donc inséparable, chez Federico García Lorca, de la souffrance («dolor») qui l'accompagne toujours et lui donne son véritable sens.
} 
arbres de son paradis perdu, soit dans le jardin de la maison maternelle, soit lors des promenades au coeur de la campagne grenadine, ensuite.

Cette assimilation progressive du peuplier, redevenu l'arbre de vie, à l'homme García Lorca est d'ailleurs si totale que le lecteur assiste, dans les lignes qui suivent, à une sorte de métamorphose qui fera dire à l'expéditeur du courrier : "Tu tarjeta de Burgos ha coloreado mi viejo estigma doloroso y ha hecho brotar de mi tronco resina y nostalgia »45. A cette date (1924), la seule vision d'une photographie rappelant l'expérience passée unique en son genre, provoque donc dans la mémoire affective du correspondant le retour d'émotions et de sensations elles-même si singulières, que celui qui les ressent à nouveau éprouve aussitôt l'impression de se transformer en être-peuplier physiquement affligé de plaies soudain rouvertes, à la manière de 'stigmates'. Et ce, jusqu'à porter les marques subitement visibles d'une Passion sans cesse revécue, après avoir avoué s'être remis à saigner d'une « douleur » soudain ravivée à l'écho de la récente «carte postale de Burgos ». Or, la plaie ainsi béante n'est autre que celle de l'homme-arbre qui, en quelque sorte métamorphosé une nouvelle fois (il dit «mon tronc»), sent couler en lui et hors de lui, désormais, de la sève épaisse à la place de sang.

Toutefois, cette sorte de rosée terrestre qui lui donne néanmoins l'impression de lui avoir un jour transmis une parcelle d'immortalité céleste, transpire maintenant de ses blessures à la façon d'une « résine de lumière et de nostalgie », comme pour signifier que c'est en réalité un ultime rayon d'espoir, liquide qui s'échappe de son corps meurtri, en proie aux effets d'un véritable calvaire. N'est-ce pas en effet l'humeur ombreuse, la substance mélancolique de l'ami en proie au regret de quelque passé disparu, qui lui sert d'encre pour s'adresser à son interlocuteur dans cette lettre ? Mais comment expliquer, en outre, la mutation de la 'bile noire' hipocratique issue du peuplier noir d'hier, en humeur résineuse davantage propre à quelque conifêre de la famille du «pin »?

Tout se passe dès lors ici comme si l'expéditeur du message à transmettre, le signataire Federico García Lorca, avait évolué à l'image de la transformation de ce symbole central du « chopo-pino », lequel, du cosmos jusqu'à I'homme qui l'habite, couvre désormais tout le champ de la pensée créatrice, de sa présence et de sa puissance : arbre vital à la fois que mortifère, dont la régénération périodique évoque le cycle des morts, mais également la possibilité des renaissances, et reflète donc l'existence de l'être dans sa difficile dynamique même. Ainsi que le rappelle en effet Mircea Eliade à propos de l'arbre : «S'il est chargé de forces sacrées, c'est qu'il est vertical, qu'il pousse, qu'il perd ses feuilles et les récupère et que, par conséquent, il se régénère : il meurt et renaît d'innombrables fois " ${ }^{46}$

En un instant donc, grâce à l'intervention de la mémoire affective soudain réactivée par la vue d'une carte postale représentant ce centre initiatique lorquien particulièrement marquant, le miracle inespéré donne dès lors au lecteur l'impression d'avoir lieu. Brusquement, la relation directe passagèrement recréée avec l'univers

\footnotetext{
$45 \mathrm{lbid}$. «Ta carte postale de Burgos a coloré mon vieux stigmate douloureux et a fait jaillir de mon tronc une résine de lumière et de nostalgie", ibidem.

${ }^{46}$ Mircea Eliade, Traité d’Histoire des religions, préface de Georges Dumézil, traduction du roumain, par $\mathrm{M}^{\mathrm{me}}$ Carciu, Jean Gouillard, Alphonse Juilland, Mihai Sora et Jacques Soucasse, édition revue et corrigée par Georges Dumézil, Paris, Payot, « Bibliothèque scientifique », 1949 ; nouvelle édition, 1964 ; 1974.); « Petite bibliothèque Payot », 1977; 1983 ; 1989, op. cit., p. 235.
} 
lié à l'existence du petit garçon d'autrefois, puis de l'adolescent plus tard en voyage universitaire, se rétablit dans toute sa force interne, restituant à l'homme de vingt-six ans la quintessence de ses premières émotions, avec l'évidence des sensations récupérées : en lui restituant simultanément la couleur (le «vert»), le son et le mouvement (du «vent» de jadis dans les ramures), en compagnie des anciens sentiments remontés à la surface dans toute leur complexité symbolique inconsciente. Aussi bien le correspondant s'était-il écrié d'emblée, sous l'effet du rôle actif d'un «coeur» qu'il sentait battre à nouveau : "Qué dulce recuerdo, lleno de verdad y de lágrimas», ou encore : «Mi corazón como nunca estará de vivo, lleno de dolor y gracia eterna ${ }^{47}$.

Et pourtant, en dépit de cette illusion de la possibilité d'un sincère et authentique retour de l'auteur aux sources de lui-même -car le «souvenir» ainsi émergé s'avoue dans toute sa «vérité» profonde, à cette date -, il ressort néanmoins de l'analyse détaillée des lignes citées qu'une telle invitation au voyage intérieur suppose également la mise en oeuvre métaphorique de toute une démarche complexe, supposant l'inexorable cheminement vers l'échec affectif, voire spirituel : ressenti non seulement par l'homme (ici l'auteur de la missive), mais encore par l'artiste (conscient à la fin de ces lignes d'une certaine impuissance créatrice, à travers « i la alegría tristísima de ser poeta! », « la très triste joie d'être poète! »).

Apparemment, la sombre pensée-peine est bien la source du mécanisme de mutation des images effectué, une fois encore, en direction d'un véritable Chemin de Croix personnel vécu et revécu par le poète-arbre que la vie a blessé et vide de sa substantifique moëlle. A l'heure où ce sont aussi des «larmes» issues du précieux «souvenir» passé qui remontent aux yeux, témoignant de l'impossible rêve initialement promis au coeur-vérité. Quant à l'autre constat proposé sur ce point par le correspondant : «Mon coeur comme je ne l'aurai jamais plus, plein de vie, de douleur et de grâce éternelle », il montre que le progrès en direction d'un approfondissement de la «connaissance» de soi - c'est-à-dire en réalité de celle cherchée et poursuivie en direction de son «âme »-, reste inséparable, à ce stade, de la souffrance qui accompagne toujours chaque progrès à faire et transforme de la sorte l'escalade, puis le passage par « la porte étroite », en un martyre permanent. Car, après l'avoir définitivement fait renoncer à la reconquête d'une «grâce » spirituelle, toute de beauté et de pureté, - comme telles de caractère divin -, ce centre de l'affectivité qu'est « el corazón » ne pourra plus qu'agir en ennemi. C'est-à-dire faire redécouvrir et ressentir jour après jour, à l'homme-peuplier-pin, la réalité quotidienne du tourment insupportable, fruit de cette « douleur » morale et physique signifiée au niveau métaphorique de ce que l'auteur appelle «mon vieux stigmate », en ce sens devenu l'expression artistique privilégiée de l'empreinte indélébile laissée sur son «tronc », partout entaillé.

II convient dès lors de noter que le procédé en question, développé dans la fin de sa lettre par le poète andalou, non seulement témoigne clairement de sa progression artistique en cours dans les années 20-25, tout en le montrant déjà sous l'aspect de plus en plus attaqué, physiquement et moralement, qu'il présentera ensuite dans d'autres poèmes : tels la «Casida des branches "48 et le «Sonnet de la douce plainte ${ }^{49}$. Quelques dix ou onze ans en effet avant d'avoir composé l'un et l'autre texte,

\footnotetext{
47 Ibid., ibid.

${ }^{48}$ Divan du Tamarit, Casidas, III, «Casida des branches», La Pléiade, T. I, op. cit., pp. 606-607. Diván del Tamarit, Casidas, III, « Casida de los ramos ».

${ }^{49}$ Sonnets de l'amour obscur, «Sonnet de la douce plainte», T. I, op. cit., p. 617. Sonetos de amor, II, « Soneto de
} 
l'auteur de la lettre citée et commentée offre ainsi à son lecteur un exemple fondamental de son avancée littéraire, y faisant une démonstration terrifiante, aussi nécessaire à la compréhension vitale de l'homme de chair, qu'à la perception évolutive de l'homme de plume.

\section{Tout au bout du chemin de l'écriture des métamorphoses menant de la « Casida des branches » au «Sonnet de la douce plainte » : vers l'ultime destin tragique du moi-corps-pommier amputé de la Huerta del Tamarit, devenu poète-arbre-corps ébranché sans nom.}

Nombreux certes, oui, nombreux sont les poèmes que nous avons analysés au sein de l'œuvre lorquienne, et qui développent d'un vers à l'autre et d'une année à l'autre ces formes sans cesse en transformation d'elles mêmes, venues exprimer l'effrayant mécanisme visionnaire en marche de l'homme-arbre, chaque jour plus amoindri et mutilé... Deux exemples particulièrement significatifs de l'aboutissement du lent et complexe processus créateur ainsi mis en oeuvre sur des années par le poète de Grenade, à partir de l'écriture du corps masculin-arbre souffrant, seraient certainement ceux cités antérieurement et qui viendront conclure notre approche du thème véritablement sacrificiel, ici abordé. Le premier est en effet la « Casida de los ramos », un poème de Diván del Tamarit, daté du 26 décembre $1934^{50}$. Et le second nous renvoie vers « El soneto de la dulce queja », appartenant pour sa part aux derniers «Sonetos de amor », dits « de l'amour obscur », de datation très incertaine, voire parfois inexistante.

Dans la Casida, extraite d'un recueil que l'on considère par ailleurs souvent comme le « testament poétique » de García Lorca, l'auteur évoque à travers une sombre tonalité destructrice et un style de rejet personnel tout à fait particulier le jardin - jadis pourtant paisible - de la propriété familiale qui lui était si familière ${ }^{51}$. Et le lecteur a l'impression que si testament il y a là, il est bien celui d'un être créateur au seuil d'un crépuscule de l'âme et du corps définitif cette fois, néanmoins à l'origine de nombre de ses plus belles strophes dans ses derniers recueils. Comme sous l'effet d'un mystérieux enchantement, sans nul doute maléficieux dont il est victime, l'auteur s'y livre donc de façon masquée à travers sa présence-absence; faisant en sorte de distiller au lecteur et commentateur, à leur tour captifs du charme, la quintessence d'un filtre magique qui paralyse et laisse sans voix les divers acteurs du drame secret en cours, ainsi annoncé à l'heure fatidique où : "Sous les arbres du Tamarit / sont arrivés les chiens de plomb / attendant que tombent les branches / attendant que seules se brisent »; puis finalement clos ensuite, à l'instant fatal où «Sous les arbres du Tamarit / il est beaucoup d'enfants très flous / attendant que tombent mes branches

la dulce queja », $\mathrm{OCl}$, p. 940

50 F. G. Lorca, Diván del Tamarit, «Casida de los ramos», OCIII, op. cit., p. 591. «Casida des branches», qui parut en version préoriginale, dans le numéro 1 de la revue Ciudad, du 26 décembre 1934, à Madrid. Dans l'édition française, se reporter à l'édit. de A. Belamich, in op. cit; pp. 606-607. Pour des explications complémentaires relatives aux manuscrits et variantes, cf. aussi Diván del Tamarit, Notes et variantes, in op. cit., p. 1596.

${ }^{51}$ Un oncle du poète avait, en effet, une propriété nommée «la Huerta del Tamarit», près du Genil. Le terme désignait, dans la langue des conquérants venus d'Afrique du Nord, le quartier où se trouvait également la «Huerta de San Vicente» appartenant à la famille Lorca. Nous renvoyons le lecteur à l'Introduction de Jorge Guillén intitulée : «Federico en Persona», «Prólogo», «Expectación», in OCl, op. cit., pp. LXXVII-LXXXI. Cf. aussi I. Gibson, F. G. Lorca I, De Fuente vaqueros a Nueva York (1898-1929) , $2^{\circ}$ édit., Barcelona, Grijalbo, 1985, pp. 197-228. 
/ attendant que seules se brisent ${ }^{52}$. Et chacun retrouve là, sous la plume crissante du moi lyrique, l'essence de ce qui constitue partout et toujours la clé essentielle de la genèse de ses vers : à savoir la restitution créatrice d'une mémoire affective issue du verger premier de l'être-peuplier blessé, en permanente métamorphose végétale métaphorique de lui-même ; comme c'est le cas dans ces strophes très suggestives d'un pronostic fatal, émis par une voix poématique au son oraculaire, donc éminemment créatrice, étroitement en relation de passage mortel avec un arbre central de son passé cordial.

Or, si le locuteur avertit d'abord en ces termes, de la menace qui plane dès la première strophe : "Por las arboledas del Tamarit / han venido los perros de plomo / a esperar que se caigan los ramos, / a esperar que se quiebren ellos solos", il conclut sur ces mots ne laissant aucun doute sur l'issue finale attendue : «Por las arboledas del Tamarit / hay muchos niños de velado rostro / a esperar que se caigan mis ramos, I a esperar que se quiebren ellos solos". Et sans doute n'échappe-t-il à personne qu'au-delà du procédé anaphorique utilisé à titre d'ouverture et de fermeture, un glissement fondamental s'est effectué d'un avant dernier vers à l'autre, en particulier quand le possessif de première personne 'mes (branches)' est venu remplacer l'article défini 'les (branches)'. Bientôt placée sous le signe d'une saison automnale à caractère hautement symbolique, 'la Huerta' évoquée -, laquelle ne s'avoue d'ailleurs pas comme telle au départ - ne présente plus guère de point commun avec l'autre jardin réel connu, témoin des activités quotidiennes de jadis ou des jeux d'autrefois. Non, car le décor poétique créé, tout imprégné d'une atmosphère pesante d'attente angoissée, devient d'emblée l'envers du Paradis de l'enfance, mais aussi le décor inversé de la liberté et de la joie : à travers l'obscur danger qui s'y dessine déjà, peu à peu profilé aux contours d'une sentence mortelle. Le paysage imaginaire lorquien est ici constitué d'allées plantées d'arbres, confondus dans une indistinction suspecte d'où un seul d'entre eux émergera ensuite, aussi emblématique que lourd de connotations, sous sa forme de «pommier » : «Le Tamarit a un pommier / et une pomme de sanglots / Un rossignol 'tient' les soupirs / Qu'un faisan chasse en la poussière ${ }^{53}$. Et tandis que les anonymes silhouettes végétales semblent soudain mystérieusement traquées par les molosses ${ }^{54}$ au redoutable caractère saturnien, en train de guetter leur proie sans relacher leur vigilance, d'autres jeunes spectateurs venus ensuite les rejoindre se trouvent donc présents à leurs côtés, comme pour asister au démantè-

\footnotetext{
52 "Casida de los ramos», ibid. ibid., La traduction de la Pléiade dit : " Il est beaucoup d'enfants voilés », le texte espagnol étant « de velado rostro ». Jorge Guillén précise sur ce point : «Según la primera estrofa, a las arboledas del Tamarit han venido los perros de plomo; según la última estrofa, vienen los niños de rostro velado. Es la misma angustiosa espera. ¿ Y de qué? Ramajes y troncos aparecen empujados, y no por el agua o por el viento, sino por la penumbra, también henchida de grandeza monumental»...»Van a caer o quebrarse los ramos -o ramas- del Tamarit : los perros o los niños -perros de plomo, niños velados - vienen a presenciar la catástrofe», Jorge Guillén ,»Expectación», in OCl, op., cit., p. LXXX.

53 «El Tamarit tiene un manzano / con una manzana de sollozos. / Un ruiseñor agrupa los suspiros/ y un faisán los ayuhenta por el polvo ", ibid., ibid. Jorge Guillén dit à propos de «ces êtres jamais vus, destinés à manifester une émotion réelle» : «Por eso el poema acoge esta serie de símbolos concordantes : perros de plomo, una manzana de sollozos, un ruiseñor que apaga los suspiros, un faisán que los ahuyenta. Esta fruta y esos animales de prodigio poseen una razón común de ser : todos están murmurando una angustia y una espera», Jorge Guillén, «Expectación», in op., cit., pp. LXXIX-LXXX.

54 Pour d'aussi mystérieuses raisons, le souvenir revient des deux vers du Romancero gitano : «Tienen por eso no lloran, / de plomo las calaveras», se profilant ici à l'horizon de la mémoire du lecteur. Cf «Romance de la Guardia Civil española», 15, OCl, vers 4-6, op. cit., p. 426. Car la valeur symbolique du «plomb» qui y pèse de tout le poids de son indifférence et de sa lourdeur est la même, ainsi que la sensation d'une dureté et d'une cruauté porteuses de mort, chez ceux, gardes ou chiens de garde, à caractère féroce.
} 
lement progressif du sujet atteint dans ses forces vives,puisque mutilé, ramure après ramure, au cours d'une lente et douloureuse agonie personnelle. Le moi lyrique en effet, tronc-corps-pommier attaqué de l'intérieur et devenu incapable de déjouer la surveillance de ses gardiens, impuissant à surmonter l'épreuve du temps sur ses branches-bras, renoue ici avec l'antique chemin créateur supposant avatars et métamorphoses formelles aux allures de sentence d'ordre supérieur, conduisant le locuteur vers des profondeurs infernales terrifiantes.

Passagèrement, pourtant, aurait pu venir, peut-être, l'heure d'une embellie, quand le texte de la troisième strophe poursuit, à la manière d'un refrain populaire allègrement fredonné dans une chanson véhiculée par la voix de tradition orale : «Pero los ramos son alegres, / los ramos son como nosotros. / No piensan en la lluvia y se han dormido, / como si fueran árboles, de pronto „55. Car, à la manière d'une baguette magique, la branche de pommier paraît être dotée parfois du pouvoir particulier de faire disparaître la tristesse, comme si elle émettait soudain des sons étranges, charmeurs, capables de renouveler l'être d'une «joie» neuve elle-même issue d'un «sommeil» réparateur, puisque porteur de songe. Mais certainement les apparences sont-elles trompeuses, quand se manifestent les effets de cette autre magie qui est à présent celle du poème derrière lequel se dissimule partout le péril omniprésent, toujours prêt à resurgir. Ainsi, quand par exemple, quand règne l'autre mystère qui fait dire, à l'imparfait : «Sentados con el agua en las rodillas / dos valles esperaban al otoño. / La penumbra con paso de elefante / empujaba las ramas y los troncos ${ }^{56} . .$.

Et sans doute faut-il remarquer que le vers «Mais les branches ont leur gaieté» (littéralement : «sont joyeuses»), établit bientôt subtilement une relation à l'homme, non pas en tant que personnalité individuelle, mais comme personnage collectif du poème, à travers l'assimilation réalisée par l'intermédiaire de la première personne du pluriel qui suit : «les branches sont comme nous sommes». / Oublient la pluie et puis s'endorment / telles des arbres, rapidement. » Humanisées, dotées de la faculté d'oublier la tristesse qui caractérise leur nature, au même titre que les êtres pensants, les rameaux sont de la sorte dotés de la faculté de vivre la même expérience destructrice d'un enchantement coupable, d'un faux rêve d'immortalité qui les conduira (en réalité qui les a déjà conduites) à leur perte. Aussi bien, l'impression première préalable éprouvée par le lecteur d'un moment d'insouciance légère, au fil de ces vers marqués au sceau d'une musique-bonheur mensongère, n'est-elle qu'un leurre, quand le rappel du destin fatal qui pèse sur les éléments du décor comme sur les individu vient sonner le glas de manière très originale, en montrant qu'une mémoire qui ne joue pas son rôle, au niveau des ramures d'un oubli coupable, occasionne la perte de l'arbre tout entier. II est donc très révélateur, dans le cas présent, que le créateur transforme une aventure mythique collective de l'humanité souffrante en une véritable épreuve

\footnotetext{
55 «La Casida de los ramos», Ibid. Trad, p. 607. Jorge Guillén commente : «Los ramos son alegres como nosotros cuando olvidamos o ignoramos, y no saben que van a caer y quebrarse ellos solos por culpa de una interna fatalidad, completada por el empuje de la penumbra», «Federico en Persona», «Prólogo», «Expectación», in OC., 1986, I, op., cit., p. LXXXI.

56 «L'eau étalée sur leurs genoux/ deux vallées attendaient l'automne. / La pénombre au pas d'éléphant / poussait les branches et les troncs » «, op. cit., p. 607. Le commentaire de Jorge Guillén est le suivant, à propos de ces vers : «Es la espera del otoño compartida por el hombre y por dos valles, concebidos con una grandeza de monumento : los valles están sentados y el agua se les sube a las rodillas. No importa la incoherencia real de esos enlaces; los ve la imaginación y los retiene la emoción que en ellos se encauza y patentiza», ajoutant : («Esta penumbra con paso de elefante acompaña de manera coherente, dentro de la misma estrofa, a los dos valles sentados y al agua en la s rodillas»), Jorge Guillén, «Expectación», in op., cit., p. LXXX.
} 
commune du monde environnant, conduisant en direction d'une véritable descente aux enfers sur le plan personnel, lorsqu'il passera de l'utilisation de la première personne du pluriel (nous) à l'emploi de la première du singulier (je).

Coupable une fois encore d'on ne sait quelle faute commise, et condamné à mourir de corps, c'est-à-dire dans ce cas de désintégration de matière d'arbre, l'auteur des vers sait d'avance qu'il subira un véritable châtiment castrateur, non sans échos biographiques et littéraires, parfois anciens, ou plus récents. Ainsi remonte dans la mémoire du lecteur les lointaines remarques de nature artistique autant que charnelle, faites par le correspondant à Antonio Gallego Burín, durant l'été 1920 : « iSi vieras qué puestas de sol tan llenas de rocío espectral !...este rocío de las tardes que parece que desciende para los muertos y para los amantes descarriados, ique viene a ser los mismos ! iSi vieras qué melancolía de acequias pensativas y qué rodar de rosarios de norias! Yo espero que el campo pula mis ramas líricas este año bendito con las rojas cuchilladas de las tardes ${ }^{57}$. Ou encore ces autres constats amers réservés à Jorge Zalamea (1), au mois d'août 1928 : « [...] Yo hablo siempre igual y esta carta lleva versos míos inéditos, sentimientos de amigo y de hombre que no quisiera divulgar. Quiero y retequiero mi intimidad. Si le temo a la fama estúpida es por esto precisamente. El hombre famoso tiene la amargura de llevar el pecho frío y traspasado por linternas sordas que dirigen sobre él los otros [...] „58; suivis des aveux et conseils de l'expéditeur à son ami, sur les deux plans de la vie et de la créativité : «Me apena que te pasen cosas malas. Pero debes aprender a vencerlas, sea como sea...Todo es preferible a verse comido, roto, machacado por ellas. Yo he resuelto estos días con voluntad uno de los estados más dolorosos que he tenido en mi vida.[...] Y luego... procurando constantemente que tu estado no se filtre en tu poesía, porque ella te jugaría la trastada de abrir lo más puro tuyo ante las miradas de los que no deben nunca verlo $\gg 59$.

On sait aujourd'hui que le 6 août 1936, par exemple, une escouade de phalangistes commandée par le responsable du massacre des anarchistes à Casas Viejas, Manuel Rojas Feigespán de bien sinistre mémoire, avait fait irruption dans la Huerta, fouillant aussitôt les lieux sans ménager aucunement les hôtes qui les occupent. Le prétexte de leur intrusion impromptue serait de découvrir un émetteur qu'ils ne trouverontnt évidemment pas, mais qu'ils prétendent caché dans la maison ou le jardin, et qui serait censé servir au poète pour faire passer des messages clandestins aux Russes. Il est vrai que le lendemain, la famille Lorca n'hésitera pas à aider un jeune architecte en péril dans une échappée à travers champs, puis en favorisant son évasion jusqu'à la frontière de la zone républicaine. Federico, qui aurait pu l'accompagner dans sa fuite, mais qui refusa d'abandonner les siens en proie à diverses menaces accrues, se souvint-il, ce soir-là, de ce qu'il avait vu et pressenti si obscurément, dans sa «Casida des branches »? À l'heure où le jardin-verger de la paix et du bonheur d'antan était devenu, pour de mystérieuses raisons, en de sombres circonstances mal définies, le centre de convergence de tous les dangers mortels réunis, présentant

\footnotetext{
57 Carta à Antonio Gallego Burín (1), [Asquerosa, 27 (¿Agosto 1920?)], Epistolario, I, op. cit., p. 80. Cf . Correspondance, À Antonio Gallego Burin, Asquerosa, 27 [août 1920], Pléiade I, op. cit., p. 989.

58 Carta à Jorge Zalamea (1), [Granada, Agosto 1928], (« Fragmentos »), Epistolario, II, op. cit., p. 577. Cf . Correspondance, À Jorge Zalamea, Grenade, [Fragment d'une lettre, août 1928], I, op. cit., p. 1152.

59 Carta à Jorge Zalamea (2), [Granada, Agosto / Principios de septiembre, 1928], Epistolario, II, op. cit., p. 582. Cf . Correspondance, À Jorge Zalamea, [Grenade, septembre 1928], I, op. cit., p. 1154. [Granada, finales de Agosto 1928], («Fragmentos »), Epistolario, II, op. cit., p. 582. Les soulignements sont de l'auteur.
} 
le caractère cauchemardesque des scènes déjà entrevues :

Ce qui rendrait toutefois ensuite sa situation de plus en plus inquiétante serait la brusque multiplication, les jours suivants, de présences inopportunes à l'intérieur de la propriété sous des prétextes divers ; car avec de telles incursions sans motif réel, l'hostilité croissante à l'égard des propriétaires et de leurs domestiques allait se montrer sous son vrai jour de règlements de comptes féroces de la part de voisins, si ce n'est de familiers, acharnés à leur perte. Il est frappant, en outre, que les méthodes employées désormais au grand jour aient été systématiquement celles de l'insulte grossière, de la plus froide accusation, quand ce n'est pas d'exactions immédiates, pratiquées sur des prétendus coupables dont il faut tirer rapidement renseignements et preuves, quoi qu'il advienne et quels que soient les moyens utilisés pour y parvenir.

Ainsi le 9 août, le domaine serait à nouveau envahi par des individus peu recommandables, venus chercher trois des frères d'un ouvrier agricole nommé Gabriel Perea Ruiz, accusés avec des complices de leur parentèle d'être 'un rouge assassin' dont ils veulent retrouver immédiatement la trace. Faute de trouver les coupables présumés au logis, les intrus s'en prendraient violemment à ses proches, malmenant et terrorisant femmes, vieillards et enfants compris, puis frappant du fouet et du gourdin un autre frère qui se trouvait là. Celui-ci, attaché à un arbre, serait alors flagellé et assommé sans pitié à l'aide d'un nerf de bœuf, pour la seule raison qu'il devait bien savoir où se cachaient les coupables et qu'il allait avouer. C'est durant cet épisode insoutenable que García Lorca, pourtant ennemi de la force brutale, devait s'interposer courageusement, avant d'être accablé d'injures, jeté à terre puis roué de coups à son tour. L'un des membres de la troupe des envahisseurs dira ensuite avoir reconnu en lui, sur le terrain, « le petit ami pédé de Fernando de los Ríos », l'homme certainement le plus haï de la droite au pouvoir. Et sur cette double attaque infamante d'ordre personnel et politique, les visiteurs furieux avaient fini par ressortir, en emmenant avec eux le gardien pour le faire parler «par d'autres moyens ». Mais en partant, ils conseilleraient personnellement à García Lorca de ne pas bouger de Grenade, et de ne plus sortir de chez lui : l'auteur, sous haute surveillance, serait désormais assigné à résidence et devrait s'en tenir strictement aux ordres reçus ; y compris si on revient le chercher pour l'arrêter, afin de procéder à diverses vérifications, lui est-il spécifié.

Les vers antérieurement étudiés, ainsi que ceux qui seront analysés, rédigés dans l'un des sonnets de 'l'amour obscur' avaient de leur côté déjà évoqué de tels comportements brutaux pour forcer le passage en pénétrant chez l'habitant ; l'auteur avait même envisagé la venue incongrue d'assaillants prêts à lâcher des insultes en se livrant à des commentaires infamants, suivis de sévices physiques. L'écrivain luttant sur tous les fronts était en effet depuis longtemps l'objet de sévères critiques relatives à l'engagement de sa vie publique, et victime de maints commérages concernant son existence privée. Certes, on lui reprochait ses prises de positions politiques tranchées en faveur des droits de l'homme et ses franches déclarations contestataires contre les injustices, bien davantage encore que ses relations de caractère homosexuel, sur lesquelles les autorités au pouvoir ont plus tard voulu trop longtemps mettre l'accent, afin de minimiser les causes politico-historiques réelles de sa mort planifiée et programmée au plus haut rang de l'armée franquiste. Mais il n'en est pas moins qu'il y avait là un prétexte de plus, saisi et utilisé pour le traîner honteusement dans la boue, à l'heure de l'arrêter, de le faire prisonnier, puis de l'exécuter. C'est ainsi que l'artiste visionnaire avait écrit, dans les tercets de «L'amour endormi sur le sein du poète »: 
"Un groupe de passants saute dans nos jardins / à l'affût de ton corps et de mon agonie / en selle de chevaux aux verts crins de lumière. / Mais ne t'éveille pas du dormir, ô ma vie. / Entends mon sang brisé en l'écho des violons ! / Vois comme on nous épie et toujours on nous guette $\gg ! 60$

Or précisément, c'est bien là de telles intrusions qu'il s'agit de dénoncer la possibilité, ou la réalité, dans la Casida analysée où la voix poématique qui s'élève, se dit précisément gagnée par une sorte de mal, lèpre ou gangrène répandue parmi les rameaux jusqu'à provoquer leur démantèlement et leur chute, comme dans le cas de membres humains attaqués, 'rongés, brisés, broyés', donc nécessairement 'émondés', à l'arrivée du poème.

\section{De la Casida au Soneto}

Le Diván del Tamarit était pratiquement achevé en 193461. Prenant alors quelque recul avec d'autres formes de création ${ }^{62}$, Federico García Lorca allait se remettre un an plus tard à écrire des poèmes d'amour, des sonnets venus constituer l'ensemble portant le nom de Sonetos de amor : en réalité sa dernière oeuvre poétique ${ }^{63}$. Dès le début du recueil, le ton est donné : «iAy voz secreta del amor oscuro », dit l'un des vers douloureux d'un poème sans titre ${ }^{64}$, exprimant par là même le cri authentique sous-jacent, pourtant délicat à divulguer, lancé depuis les profondeurs de la genèse en cours par le locuteur souffrant jusqu'à son dernier jour mille morts affectives arborifères. Celui-ci n'y dévoile-t-il pas, tout en prétendant la masquer, la passion véhémente, cachée, interdite ressentie, en ce sens toujours objet de critiques malveillantes de la part d'observateurs partout et toujours aux aguets?

Et à ce moment de sa vie et de son oeuvre, ne cherche-t-il pas à traduire en termes universels, grâce au retour vers des formes «traditionnelles»65 imprégnées d’influences avouées de Góngora ${ }^{66}$ ou empreintes de certains accents tragiques de

60 “L'amour endormi sur le sein du poète », deux derniers tercets, Pléiade II, op.cit., p. 620. «El amor duerme en el pecho del poeta ", OCl, op.cit., p. 948.

${ }^{61}$ C'est-à-dire après le travail réalisé pour le LLanto por Ignacio Sánchez Mejías, également composé entre septembre et octobre 1934, (Le torero ami de García Lorca était mort le 13 août au matin, après avoir été blessé le 11 août dans les arènes de Manzanarès), puis lu intégralement le 4 novembre chez son ami Carlos Morla Lynch, (Cf. En España con Federico, op. cit., p. 422), le dramaturge devait se consacrer entièrement au théâtre jusqu'en mai 1935, date à laquelle il allait achever Doña Rosita la soltera.

${ }^{62}$ C'est en effet avec une certaine distance que le poète commence à composer la série de poèmes intitulée Sonetos del amor oscuro., sans doute au cours de l'été suivant (1935). Parmi eux, un petit groupe de textes que l'on pourrait intituler les «sonnets de la séparation» portent la trace du séjour à Valence de García Lorca, dans la première quinzaine de novembre 1935. II s'agit des sonnets : «Soneto de la dulce queja», OCI, op. cit., p. 940; «El soneto de la carta», op. cit., p. 942 («Le poète demande à son amour de lui écrire», op. cit., pp. 617-18); «El poeta habla por teléfono con el amor», op. cit., p. 944; «Soneto Gongorino» en que el poeta manda a su amor una paloma», op; cit., p.946. Voir sur ce point la Notice de ces textes in La Pléiade, édit. A. Belamich, op. cit., pp. 1599-1602. Cf. aussi Notes et variantes, id., pp. 1603-1609.

63 Contrairement à ce qu'il affirme à Felipe Morales, dans l'interview du 7 avril 1936, le livre des «Sonnets» n'était pas achevé lorsque le poète, réfugié chez Luis Rosalès dans la première quinzaine de juillet, consacre encore ses derniers jours à leur composition. Le temps a donc manqué pour permettre au poète, assassiné quelques jours plus tard, d'amplifier et de terminer ce qui devait rester comme sa dernière production artistique en vers.

${ }_{64}$ Vers 1 d'un sonnet qui ne porte pas de titre, [« iAy voz secreta del amor oscuro»], OCI, op. cit., p. 947. «Ô voix secrète de l'amour obscur !», Pléiade, I, op. cit., p. 620.

${ }^{65}$ García Lorca déclare de ce point de vue à Felipe Morales, le 7 avril 1936 :»El libro de Sonetos, significa la vuelta a las formas de preceptiva después del amplio y soleado paseo por la libertad de metro y rima», in «Una conversación inédita con F. García Lorca, índice de las obras que dejó el gran poeta». «Los cuatro libros por publicar», OCIII, op. cit., p. 676.

66 En témoigne, par exemple, le «Soneto gongorino en que el poeta manda a su amor una paloma », VIII, OCI, op. cit., p. 945. Cf. «Sonnet à la manière de Góngora dans lequel le poète envoie à son amour une colombe ", 
Quevedo ${ }^{67}$, des sentiments à résonnance personnelle ? Sans doute ; même si l'être affecté, caché derrière l'écrivain blessé de l'ombre, s'efforce de dérober l'essentiel de sa vie privée à ces 'lanternes sourdes que braquent sur lui les autres' dont il avait préalablement évoqué l'éclairage néfaste, susceptible de le mettre trop en lumière, dans les lignes du courrier cité de l'automne 1928, adressé à son ami Jorge Zalamea ${ }^{68}$.

Dans le «Soneto de la dulce queja»69, l'élaboration artistique paraît répondre exactement à l'analyse préalable de l'auteur qui avouait : «Je parle toujours le même langage», tout en confessant : «j'ai confié ...des sentiments d'ami et d'homme que je ne voudrais pas divulguer». II renoue là, en fait, avec l'une des ultimes déclarations faites par lui, dont nous donnons la traduction : "C'est pourquoi je ne conçois pas la poésie comme une abstraction, mais comme une chose réelle qui existe, qui me côtoie. Tous les personnages de mes poèmes ont vécu. L'essentiel, c'est de mettre la main sur la clef de la poésie. Au moment où l'on s'y attend le moins, vlan !! La porte s'ouvre et le poème arrive, éblouissant[...]La poésie n'a pas de limites. Elle peut nous attendre, assise au seuil de la porte, dans l'eau d'une fontaine, perchée sur la branche d'un olivier... » ${ }^{70}$.

Certes, puisqu'il s'agit bien pour lui d'utiliser, après le langage du peuplier, du pin, du pommier, de l'arbre-corps masculin tourmenté, tordu et amputé, celui toujours à décrypter d'une souffrance tenace, éprouvée et dite charnellement, cordialement, spirituellement, au contact d'autres essences, non seulement issues de paysages réels, mais encore jaillies de son moi-jardin intérieur onirique ou visionnaire. Or, après la longue série d'expériences poétiques angoissées et angoissantes qui précèdent, révélatrices d'une même quête anxieuse d'amour envisagée sous toutes ses formes ; et suite à une lente prise de possession d'espèces peu à peu modifiées, comme telles à l'origine de nombreuses métamorphoses d'images, ce sera désormais le seul cri du poète-arbre-sans-nom cette fois, que nous entendrons, définitivement damné sur fond de crépuscule et de fin d'été.

Ainsi dans cet ultime essai en vers, d'où ressort une silhouette entre végétale et humaine impossible à reconnaître physiquement, parce que affreusement torturée dans le décor désolé imaginé ou recréé. Au terme d'un premier quatrain dans lequel la voix poématique anxieuse résonne soudain pour dire au présent, à la première personne, sa crainte de voir disparaitre l'objet de sa passion, simultanément regard posé sur lui et souffle perçu sur sa peau ${ }^{71}$, le second exprime en ces termes désespérés le chagrin douloureusement ressenti par l'amant du texte : «Tengo pena de ser en esta orilla / tronco sin ramas; y lo que más siento / es no tener la flor, pulpa o arcilla, / para el gusano de mi sufrimiento» ${ }^{72}$. Le lecteur découvre ainsi, à travers la «douce

op. cit., pp. 619-620.

${ }^{67}$ Quevedo pour lequel l'écrivain professe à l'époque une énorme admiration. Il dit dans l'entretien cité : «Hablaré en Méjico de Quevedo, porque Quevedo es España», in: «Una conversación inédita con F. García Lorca», «Mientras espera el cable de Margarita», op. cit., p. 676.

68 Cf. A Jorge Zalamea (1), [fragmentos] [Granada, agosto 1928], Epistolario, op. cit., p. 576 et svtes. Trad. « Lettre à Jorge Zalamea», Grenade, août 1928, Correspondance, op. cit., p. 1152. Cf. note 488, op. cit., p. 577.

${ }^{69}$ Sonetos del amor oscuro., «Soneto de la dulce queja», op.cit., p. 940. Cf. Sonnets de l'amour obscur, «Sonnet de la douce plainte», op. cit., p. 617

70 «Un entretien avec F. G. Lorca», 7 avril 1936, Pléiade, T II, op. cit. p. 925.

71 Op. cit., vv. 1-4: «Tengo miedo a perder la maravilla / de tus ojos de estatua, y el acento / que de noche me pone en la mejilla / la solitaria rosa de tu aliento», ibidem. Trad., op.cit., p. 617. « J'ai peur de perdre la merveille / de tes yeux de statue et cet accent / que vient poser la nuit près de ma tempe / la rose solitaire de ton souffle " (« haleine » dit le texte traduit en Français).

72 «Soneto de la dulce queja», second quatrain, vers 5-8, op.cit., p. 940. Trad., op.cit., p. 617 : «Je m'attriste de 
plainte» annoncée dès le titre du texte et qui s'élève maintenant du fond d'une «nuit obscure» source de cauchemar, que le ton est donné, avec le contenu personnel qui l'accompagne. Si le poète a choisi d'utiliser ici la forme traditionnelle du sonnet, parfois considérée comme un peu figée et à laquelle il veut redonner vie, c'est précisément pour lui insuffler de l'intérieur, à travers la contrainte formelle à laquelle il se sait obligé de se soumettre pour signifier ses sentiments, la chaleur de sa parole créatrice, absolument unique en son genre. Or de ce point de vue, il apparaît aussitôt que la voix élégiaque perçue ici sera celle née du sentiment d'incomplétude, quand la «peur» de départ cède peu à peu la place à la douleur sans remède, et quand la «peine» devient celle éprouvée par le poète-corps-arbre, errant de vers en vers à la recherche de l'autre, tel une véritable âme végétale-humaine en peine.

Toutefois, si le sujet en cause dissimule à nouveau son éros souffrant sous l'écorce rugueuse qui lui sert une fois encore de rampart allégorique protecteur - carapace vulnérable certainement désormais de plus en plus mince et enveloppe de plus en plus fragile -, il est certain également que la silhouette ici offerte au lecteur présente un aspect plus épouvantable que jamais. Car le choix de l'image centrale (au-delà des figures qui l'entourent, ainsi que des métaphores constitutives du registre poétique environnant) fait à présent de lui, non seulement un arbre sans nom, c'est-à-dire désormais impossible à identifier, mais encore ce «tronc sans branches» qui ne ressemble même plus à un arbre. Ni "chopo» (peuplier axial de tout l'échafaudage créateur lorquien), ni «álamo» (colonne textuelle structurante de nombre de vers), l'un et l'autre à la source de la majorité des poèmes rencontrés ; ni même pommier-de-larmes hier métamorphosé par le chagrin («manzano / con una manzana de sollozos», donc arbre d'une connaissance interdite et substitut lorquien de l'arbre de vie), il ne s'avoue plus qu'en terme de souche tronquée sans tête-cîme ni membrure-charpente, ou de segment décapité et estropié, au point que nul ne saurait plus deviner à quelle espèce il appartient.

Bien que toujours posé sur «la rive » de l'autre, « esta orilla »73 qui lui sert néanmoins d'ultime point d'ancrage friable, comme pour mieux alimenter son seul dessèchement par l'intermédiaire de ses racines absentées, il cherche en vain quelque onde nourricière susceptible de nourrir sa douleur de «ver » abject : « fleur, pulpe ou argile ». En ce sens, redevenu porteur du Franciscanisme lorquien originel des strophes du «Livre des Poèmes » ou du Prologue du « Maléfice de la Phalène » ${ }^{74}$, il

n'être en cette rive / qu'un tronc sans branche et mon plus grand tourment / est de n'avoir la fleur ou la pulpe ou l'argile / qui nourrirait le vers de ma souffrance », op. cit. p. 617.

${ }^{73}$ Rive symbolique, mais également référence réelle susceptible de permettre de situer exactement la composition du poème, si l'on envisage que le poète de Grenade se trouve, dans la première quinzaine de novembre 1935, sur les bords du Turia qui baigne Valence et dont on note la présence, explicite ou non, dans les poèmes rédigés à l'époque. Ainsi, le même "Soneto gongorino en que el poeta manda a su amor una paloma " déjà cité, op. cit., p. 946, où il est dit : «Este pichón de Turia que te mando, / de dulces ojos y de blanca pluma, / sobre laurel de Grecia vierte y suma / llama llena de amor do estoy parando "/ . "Sonnet à la manière de Góngora dans lequel le poète envoie à son amour une colombe » : La traduction dit : « Ce pigeon de Turia qui te retrouve/ avec ses tendres yeux, ses blanches plumes, / sur un laurier de Grèce verse et résume / la lente flamme d'amour que je souffre », op. cit., pp. 619-620. Nous proposons plutôt : "Ce pigeon de Turia que je t'envoie/ avec ses tendres yeux, ses blanches plumes, / sur un laurier de Grèce verse et résume / la flamme enflée d'amour qui me supporte».

${ }^{74}$ Le lecteur en traquera la preuve jusque dans certains vers de «Rythme d'automne » de 1920, où il entendra la voix poématique empreinte d'un Franciscanisme, lui-même teinté d'une mélancolie diffuse et bienfaitrice, s'écrier en termes de Béatitudes remontant à une époque regrettée, parce que depuis longtremps disparue : «Heureux ceux qui coupent la rose / Et moissonnent le blé !.../...Ceux que bénit d'un triomphant sourire / Le frère saint François. / Nous souffrons bien des peines / À travers nos chemins. / Nous voudrions savoir ce que nous 
se présente de manière totalement dégradée à travers les deux sentiments dont il se sent encore capable à ce dernier stade : d'abord «tengo miedo», puis «tengo pena», se donnant ainsi à voir craintivement et douloureusement comme une sorte de corps goyesque, à son tour issu des désastres de la guerre après le passage de l'ennemi. Mais n'est-ce pas là aussi, selon la vision maintenant proposée du squelette arborifère complètement mis à nu, revenir à la perception première susceptible de mettre en relation les sentiments spécifiques éprouvés avec l'humeur hippocratique particulière à l'origine de la créativité 'géniale' : tristesse et crainte d'un côté, bile de plus en plus noire de l'autre? Sans nul doute, tout en faisant ainsi renouer l'auteur sur le plan privé, à la date du texte, avec la définition traditionnelle du concept initialement issue de l'aphorisme d'Hippocrate selon lequel : «Si crainte et tristesse durent longtemps, un tel état est mélancolique» (6ème section, § 23, IV L 568) : mélancolie éminement créatrice, s'entend.

C'est dès lors de ce reste d'arbre invalide voué à l'anonymat qu'émane cependant la voix moribonde du sonnet : son « plaintif » qui se cherche à travers celui de «'amour obscur» de son inspiration menacée, à instar de sa passion de caractère cristique, : murmure non alimenté par la sève du sentiment nourricier qui constituait préalablement l'essentiel de son pouvoir de rénovation-résurrection, en lui apportant force et vie retrouvées. Une fois encore, pourtant, le je-moi du dialogue instauré avec le tu-toi de l'interlocuteur sans nom lui aussi, va chercher à dépasser le pire, pour délivrer un ultime message littéraire à l'autre, en lui adressant dans le premier tercet l'écho sourd de la « douleur mouillée » bientôt noyée, qui est alors la sienne. Et le lecteur a l'impresion d'entendre là le gémissement du 'chien' blessé par un maître cruel, à l'adresse de l'être néanmoins qualifié de «trésor occulte» dont nul ne sait où il se cache, mais qui prend partout le visage anonyme du bourreau indifférent face à sa victime, responsable d'avoir à nouveau cloué celle-ci sur le bois, tel un nouveau Christ, torturé et impuisssant ${ }^{75}$. «Federico » n'est-il pas redevenu à ce stade ce «Chien andalou », celui que Salvador Dalí et Luis Buñuel avaient pris pour cible des années auparavant, en 1929, dans leur film « Un perro andaluz »...?

Mais voici que l'appel se fait pressant, voire même supplique de dernière heure,

disent les peupliers de la rivière», in Livre de Poèmes,op. cit., pp. 100-103. Dans une lettre du 19 septembre 1918, F. G. L expliquait déjà sur ce point à Adriano del Valle : "Je travaille actuellement à mon oeuvre de Saint François d'Assise, qui est une chose tout à fait nouvelle et curieuse", sans doute un essai théâtral perdu dont il ne reste du moins aucune trace, in Correspondance, op. cit., p. 990. Les textes écrits durant l'été difficile de 1920 vibraient quant à eux des différents échos qui précèdent, à l'unisson des ramures complices : de la passion inassouvie ou inexistente, au sein d'une nature morte dans laquelle «L'automne a laissé sans feuillage /Les peupliers de la rivière» (Livre de Poèmes, «Nocturne», p. 102), et où les arbres confidents bruissent tristement, comme autant des cris de la douleur du poète : «Pater Noster pour mon amour! /(Plainte des peupliers / Et des futaies)» in_Livre de Poèmes, «Paysage», Juin 1920 , p.51. Ils se font aussi notes de la solitude et de l'abandon du promeneur: "Les champs sont dépeuplés, /Les montagnes éteintes /Et les champs déserts. /De temps en temps, tout seul, /Chante un coucou dans l'ombre /Des peupliers» (id.,»Le vieux lézard», 1920, p.70. Et résonnaient alors les accords d'un franciscanisme teinté de symbolisme, exprimés à travers le» délire» des «vers» avides de connaître le secret des arbres amis qui poussent au bord l'eau : «Heureux...Ceux que bénit d'un triomphant sourire /Le frère saint François. Nous souffrons bien des peines A travers nos chemins. /Nous voudrions savoir ce que nous disent les peupliers de la rivière»( Id «Rythme d'automne» (1920), p. 100-103).

75 " Si tú eres el tesoro oculto mío , / si eres mi cruz y mi dolor mojado, / si soy el perro de tu señorío », vv. 9-11, op. cit., p. 940. Trad., op. cit., p. 617 : «Si tu es le trésor que je recèle, / ma douce croix et ma douleur noyée, / et si je suis le chien de ton altesse »... . «Le chien» dont il s'agit dans ce vers n'est plus à ce stade celui du précédent poème. Il est au contraire l'expression de la fidélité amoureuse passant par un absolu renoncement de soi et confronté à l'autre, 'de plomb', qui le domine et le maltraite. Dans le «Sonnet» [i Ay voz secreta del amor oscuro!»], nous lisons par exemple : «iAy perro en corazón, voz perseguida», op. cit., p. 947. Trad., « Ô voix secrète de l'amour obscur », op. cit., p. 620. 
dans le second tercet : «no me dejes perder lo que he ganado / y decora las aguas de tu río / con hojas de mi otoño enajenado ${ }^{76}$. Et voici que revient maintenant l'image de la «rivière», représentée par le courant de l'autre qui l'entraîne inexorablement dans son lit pour y succomber, tandis que résonne la prière montante adressée au responsable de son malheur en marche. Or à cette étape du sonnet, le lecteur découvre qu'une volonté d'union d'une nature différente est finalement exprimée, afin de permettre les retrouvailles entre les deux partenaires que la vie a séparés. Toutefois, il s'agira là d'un étrange mariage symbolique, d'une alliance inattendue de l'arbre et de l'eau, d'une cérémonie rituelle spéciale au cours de laquelle l'amant malheureux, végétal agonique préalablement dépouillé de ses branches, et avec elles de ses «feuilles», fait à l'amour cause de son malheur, avant de périr emporté au fil de l'onde, l'offrande mortuaire de sa végétation automnale à titre de présent buccholique, guirlande ou couronne encore non flétrie ${ }^{77}$.

Comme nous le disions, d'un point de vue symbolique, le locuteur de ce sonnet vit dès lors une véritable amputation ressentie comme honteuse (ou disqualifiante) qui le place métaphoriquement en marge du monde diurne, en fait un exclus, « un chien » errant, c'est-à-dire le rejette sous toutes ses formes hors de l'ordre humain. Devenu arbre-homme-deshumanisé désormais sans nom, impitoyablement ébranché, il rejoint donc progressivement l'univers végétal nocturne, caché et invisible, depuis une passion aux allures de chemin de croix (au sens du calvaire humain qu'elle engendre et du sacrifice subi dans la chair et l'esprit qu'elle suppose ${ }^{78}$ ) ; car elle est vécue comme un martyre infernal (du fait de l'interdit qu'elle représente, de son caractère nécessairement secret et de sa nature ressentie comme affection coupable ${ }^{79}$ ). La question qui surgissait forcément dans l'imaginaire du lecteur trouvera en fin de comptes sa réponse plausible : un tel arbre-manchot peut-il être réintégré dans un cycle temporel, grâce à un nouvel usage de ses rameaux et de ses pousses ? La lecture du dernier tercet laisse en effet penser que non ; du moins pas au sens attendu, au moment où l'hommage final rendu à l'amour meurtrier se manifeste esthétiquement (avec le verbe «decorar», ou sa variante «embellecer»), en terme de cérémonie sacrificielle à volonté artistique. Puisque ce rite singulier- qui rappelle quelque mystère grec ou cérémonie antique - se déroule au moyen de l'offrande de feuilles mortes, tombées de «l'automne» du coeur, détachées des branches et du tronc lui-même déjà

\footnotetext{
76 «Soneto de la dulce queja», ibid. , « ah, garde-moi le bien que j'ai gagné / et prend pour embellir ta rivière / ces feuilles d'un automne désolé», v. 9-14, Sonnets de l'amour obscur, «Sonnet de la douce plainte», op. cit., p. 617.

77 C'est maintenant le verbe signifiant «orner et embellir « qui introduit dans l'imaginaire du lecteur la vision, présente dans d'autres morceaux, de ces "guirlandes» unissant à jamais les amants dans le tourbillon du courant : «iEsa guirnalda! / i Teje deprisa!» («Soneto de la guirnalda de rosas», op. cit., p. 939. « Sonnet de la guirlande de roses », op. cit., p. 615); «Son guirnaldas de amor, cama de herido» («Llagas de amor», op. cit., p. 941. «Plaies d'amour », op. cit., pp. 616-617); «[...] y mi llanto prendió por primera vez / coronas de esperanza por el techo» («El poeta habla por teléfono con el amor», op. cit., p. 944. « Le poète parle au téléphone avec l'amour », op. cit., p. 618).

78 D'autres «Sonnets» confirment l'existence de ce chemin de croix poétique, par exemple à travers la question : « ¿Han besado tus dedos los espinos / que coronan de amor piedra remota?» («El poeta pregunta a su amor por la ciudad encantada de Cuenca»), op. cit., p. 945. «Le poète demande à son amour après la 'ville enchantée de Cuenca', op. cit., p. 619; chemin souvent « hérissé de venin » : «Este alacrán que por mi pecho mora»(«Llagas de amor», op. cit., p. 941) ; ou d'une connaissance qui prend parfois des accents socratiques : "con cicuta y pasión de amarga ciencia» («Llagas de amor»), ibid., « Plaies d'amour »., Ibid. pp. 616-617; «iay aguja de hiel! (i Ay voz secreta del amor oscuro!», op. cit., p. 947. « Ô voix secrète de l'amour obscur »), op. cit., p. 620.

79 Le moi interroge par exemple, dans un autre poème : «¿Te acordaste de mí cuando subías / al silencio que sufre la serpiente / prisionera de grillos y umbrías ?», («El poeta pregunta a su amor por la ciudad encantada de Cuenca», p. 945. «Le poète demande à son amour après la 'ville enchantée de Cuenca', op. cit., p. 619).
} 
hivernal, saignant leur sève comme autant de blessures, puis lancées au fil d'une eau vive, à travers l'image du flot qui les emporte avec lui ${ }^{80}$.

En ce sens, le mouvement poétique ainsi envisagé renoue en profondeur, à la manière lorquienne propre, avec le mouvement inhérent aux strophes de las «Coplas » de Jorge Manrique, dans les autres vers qui disaient: "No se engañe nadie, no / pensando que ha de durar / lo que espera / más que duró lo que vió, / pues que todo ha de passar / por tal manera ${ }^{81}$. Et sans doute le sage (mais l'homme passionné refuse la sagesse) se devrait-il plutôt de méditer cette autre strophe, immédiatement antérieure : "Pues si vemos lo presente / cómo en un punto s'es ido / e acabado, / si juzgamos sabiamente, / daremos lo non venido por passado „82. Car le présent grammatical chargé de véhiculer ici l'expression craintive, mais aussi tristement souffrante, de la destruction intérieure en cours, jusqu'à déboucher sur la sensation fugitive de l'ultime fuite éperdue des rameaux envoyés vers l'eau de la rivière à travers l'impératif employé, ne saurait en aucun cas fixer le sentiment éprouvé dans un présent de certitude quelconque. Et ce, d'autant plus, que le tercet précédent s'ouvrait sur l'hypothétique «Si tu es le trésor », lourd de sous-entendu... La forme grammaticale utilisée ne saurait donc traduire que le doute en marche, l'angoisse croissante, tout en soulignant la seule durée d'une illusion savamment entretenue, finalement destinée à « se noyer » à son tour dans l'onde mouvante dont chacun sait qu'elle incarne, emblématiquement et simultanément dans les fragments conservés d'Héraclite, à la fois ce qui a été de manière éphémère, ce qui n'est pas encore et ne sera peut-être pas ; ce qui déjà s'en est allé, s'en va et s'en ira inéluctablement.

Dans cette fugace perspective comparative littéraire et philosophique, l'acte de se jeter dans le fleuve par l'intermédiaire de l'image d'une végétation élaguée que le courant toujours changeant emporte, fait implicitement le lien avec l'antique vision héraclitéenne, à travers sa théorie relative à l'eau qui, parce qu'elle coule sans s'arrêter et fuit sans cesse, devient ainsi la représentation de la fluctuation universelle, de l'incessante métamorphose des formes, ainsi que de l'impermanence de toutes choses. Quel devenir, humain ou non, peut donc être ensuite celui de ce pauvre tribut feuillu qui n'est provisoirement restitué à une temporalité vitale et affective qu'à travers sa qualité de substance périssable, c'est-à-dire livrée au seul caprice d'une nappe toujours changeante avec laquelle le présent offert n'est à nouveau uni que pour mieux s'en séparer? Car, ainsi que le rappelle le dernier fragment héraclitéen : "par la promptitude et la rapidité de sa transformation, elle (la substance en question) se disperse et se réunit à nouveau, ou plutôt, ni à nouveau ni après, c'est en même temps qu'elle se rassemble et qu'elle se retire, qu'elle survient et s'en va »83.

L'ultime rituel de dépossession dès lors accompli par l'être-bois-feuilles, définitivement aliéné selon le propre texte («otoño enajenado »), consistera donc en ce don ultime désintéressé, purement symbolique de la part du poète manchot : offrande

\footnotetext{
${ }^{80}$ Le lecteur repense ici aux vers de «Corriente lenta», poème qui accompagnait les «Meditaciones y alegorías del agua» : «(Mi corazón va contando / las horas que está dormido). El río trae hojas secas, / el río.../ El río es claro y profundo, / el río... / (Mi corazón me pregunta / si puede cambiar de sitio ».) OCl, op. cit., p. 885. « Méditations et allégories de l'eau », «Rivière lente », Pléiade, I ,. op. cit., p. 309. Car cette eau vive qui emporte dans son courant des feuilles sèches et ce «coeur» qui s'interroge pour savoir «s'il peut s'envoler» annoncent déjà le mouvement poétique de notre actuel sonnet.

81 «Coplas a la muerte del maestre de Santiago, don Rodrigo Manrique, su padre», op. cit., respectivement vers 25-27 et 19-24.

82 Jorge Manrique, «Coplas», ibid., vers 14-18.

${ }^{83}$ Héraclite, Fragments, [Citations et témoignages] traduits et présentés par J. F Pradeau, Poche, G. Flammarion.
} 
cérémonielle de ce qui est devenu l'expression même («dolor mojado») de son échec affectif et de son calvaire terrestre, livrés tous deux à l'être adoré, bien qu'indifférent, dont la course se poursuit vers une commune disparition jusqu'à l'embouchure... fuite « automnale » ornée des dépouilles végétales de l'autre. De ce point de vue, il convient certainement d'envisager le geste proposé sous l'angle du double et de l'altérité, par l'intermédiaire de ce que le texte définit comme «enajenamiento» : égarement vers un 'autrui' entendu comme «otredad», et « autreté » à son tour saisie dans toutes les acceptions du mot 'otro' («autre», «différent»,»second» et «double», défini le plus souvent chez le créateur andalou sous l'angle de «l'autre moitié» ('la otra mitad'). Il en est souvent question, ainsi que l'ont montré certains vers correspondant à la période du voyage du Poeta en Nueva York, en 1929.

Nous retrouvons dès lors ici le poète andalou qui n'est plus tout à fait lui-même, au cours de sa nouvelle expérience initiatique de mort sans vraie renaissance, si ce n'est littéraire. Car, ainsi que le montre le dernier vers de ce sonnet, le déchirement physique et mental éprouvé au terme du voyage onirique et cauchemardesque du corps-arbre en proie à sa noyade amoureuse, conséquence de sa propre mort intérieure, passe par son absolu sacrifice, jusqu'à la totale dépossession, et suppose le don de soi jusqu'à l'égarement, le désintéressement jusqu'à la perte de la raison et la folie.

L'analyse détaillée de la progression dans le temps de telles images ou métaphores constituent donc, semble t-il, l'aboutissement amnésique désespéré de l'itinéraire humain, mais aussi créateur, qui faisait s'écrier au moi lyrique, dès ses premières compositions en vers : «El poeta es un árbol / con frutos de tristeza / y con hojas marchitas / de llorar lo que ama» ${ }^{84}$ Déjà loin semble le temps pas si lointain où, dans la «Gacela de la raíz amarga», le cri était encore capable de dénoncer le drame issu de la «racine amère» : aigreur d'un fiel âcre au goût de poison, remontant depuis la base de l'être jusqu'à la pointe des cheveux, glissant tout au long du «tronc» envahi d'une douleur tenace et «coupante» comme le fil d'un rasoir, au sein d'une «nuit» devenue végétale et mutilée sous sa «fraîcheur» d'arbre : « Hay una raíz amarga [...] / Duele en la planta del pie / el interior de la cara, / y duele en el tronco fresco / de noche recién cortada/ iAmor, enemigo mío, / muerde tu raíz amarga \$ $^{85}$

Sans doute, cette terreur dernière éprouvée dans la triste douleur ressentie d'une «morsure» cruelle suggérait déjà implicitement la vision obscure du cerbère prêt à satisfaire sa faim de destruction ; et l'angoisse était manifeste, en présence de la certitude de l'impossible réconciliation de la chair et de l'âme. À l'arrivée du long et douloureux cheminement vital et artistique lorquien, le peuplier-humain sans tête et sans visage, l'homme-peuplier finalement dépossédé de son nom, de son identité, de ses branches-bras, de ses feuilles-mains-doigts, cherche néanmoins à puiser une

\footnotetext{
84 [«A las poesías completas de Antonio Machado»], strophe 8, in OCl, op. cit., p. 994. Trad., in En Marge de Livre de Poèmes, "J'aimerais laisser dans ce livre», op. cit., p. 115. Ce poème a été écrit sur la page de garde d'un exemplaire de Poésies complètes d'Antonio Machado. II est daté du 7 août 1918.

85 "Gacela de la raíz amarga»,VI, vers 1, 10-15, in OCl, op. cit., p. 578. Publiée en préoriginale, dans la revue Héroe, $n^{\circ} 6$, Madrid, 1932. Nous renvoyons sur ce point à l'étude de Bernard Sesé : «Les racines dans l'univers imaginaire de Federico García Lorca», D'»Une racine amère», in Les Langues Neo-Latines, №170-171, septdéc. 1964, pp. 44-63. L'âcreté contenue et dite renoue également avec la vision de «'arc» d'un passage vers une «rencontre» suggérant le sacrifice de Socrate et la "ciguë», dans deux vers de la "Gacela del recuerdo de amor» : «Por el arco del encuentro / la cicuta está creciendo», vers 21-22, VII, in OCl, op. cit., p. 579. Une vision très proche de celle-ci est contenue dans le dernier tercet du sonnet «Llagas de amor» : «me da tu corazón valle tendido / con cicuta y pasión de amarga ciencia», in Sonetos de amor, op. cit., p. 941.
} 
dernière fois à l'eau vive de l'Amour son ennemi de toujours, en buvant à la source de ce double guetté dont il voudrait pouvoir être à son tour le clair ruisseau et la sève nourricière. Mais il est trop tard : il n'en a plus la force et Thanatos l'attend désormais de l'autre côté du rivage du fleuve d'Eros.

...Seules nous seront-sont laissées pour l'éternité, noblesse littéraire oblige toutefois chez Federico García Lorca, les précieuses «feuilles » volantes de ces strophes sublimes, d'abord restées secretes et jamais achevées avant son arrestation puis son passage devant le peloton d'exécution : las hojas de su otoño enajenado... 